\title{
Factors Related to Collaborative Willingness in Surrogate Decision-Making Situations from the West Virginia POST.
}

Rachael Spalding

Follow this and additional works at: https://researchrepository.wvu.edu/etd

\section{Recommended Citation}

Spalding, Rachael, "Factors Related to Collaborative Willingness in Surrogate Decision-Making Situations from the West Virginia POST." (2019). Graduate Theses, Dissertations, and Problem Reports. 8203.

https://researchrepository.wvu.edu/etd/8203

This Thesis is protected by copyright and/or related rights. It has been brought to you by the The Research Repository @ WVU with permission from the rights-holder(s). You are free to use this Thesis in any way that is permitted by the copyright and related rights legislation that applies to your use. For other uses you must obtain permission from the rights-holder(s) directly, unless additional rights are indicated by a Creative Commons license in the record and/ or on the work itself. This Thesis has been accepted for inclusion in WVU Graduate Theses, Dissertations, and Problem Reports collection by an authorized administrator of The Research Repository @ WVU. For more information, please contact researchrepository@mail.wvu.edu. 
Factors Related to Collaborative Willingness in Surrogate Decision-Making Situations from the West Virginia POST

Rachael Spalding, B.A.

\author{
Thesis submitted \\ to the Eberly College of Arts and Sciences \\ at West Virginia University \\ in partial fulfillment of the requirements for the degree of \\ Master of Science \\ in \\ Psychology
}

Barry Edelstein, Ph.D., Chair

JoNell Strough, Ph.D.

Kevin Larkin, Ph.D.

Department of Psychology

Morgantown, WV

2018

Keywords: Shared decision-making, surrogates, end-of-life care, POST, collaboration

Copyright 2018 Rachael Spalding 


\begin{abstract}
Factors Related to Collaborative Willingness in Surrogate Decision-Making Situations from the West Virginia POST

Rachael Spalding, B.A.
\end{abstract}

If a patient becomes unable to adequately express preferences for medical care, another individual called a "surrogate" may be consulted to make treatment decisions. Surrogates may be asked to indicate patient preferences on the Physician Order for Scope of Treatment (POST), a new type of advance directive completed with patients who are estimated to have less than one year left to live. Research from the shared decision-making literature indicates that collaboration can be a valuable means of enhancing patient satisfaction with their decisions. The current study examined how certain psychological and demographic variables predicted the extent to which participants desired collaboration and personal involvement when serving as hypothetical surrogates and making decisions for another person across the three sections of the West Virginia POST form. One-hundred-and-seventy-two adult participants with no prior experience in a formal surrogate decision-making role were recruited from Amazon Mechanical Turk to complete the online survey. Gender predicted collaborative willingness, with women desiring more collaboration than men. A linear multiple regression using the psychological predictor variables of anxiety, intolerance of uncertainty, experiential avoidance, consideration of future consequences, and decision-making confidence contributed significantly to the prediction of collaborative willingness $\left(F(5,165)=6.04, p<.001, R^{2}=.155\right)$. Confidence was the only variable that uniquely contributed to the prediction $(\beta=.30, p<.001)$, such that greater confidence in one's decision predicted greater collaborative willingness. The model only significantly predicted collaborative willingness for the decision related to CPR, indicating that differences in the decisions may influence how surrogates approach the three sections of the POST. All of the psychological characteristics except intolerance of uncertainty uniquely contributed to the prediction of scores on the Autonomy Preference Index decision-making preference subscale. Greater decision-making confidence across the three POST decisions predicted lower scores on the API, indicating less preferences for personal involvement. Conversely, greater confidence was associated with higher total collaborative willingness scores, indicating greater preference for collaboration. This discrepancy illuminates how individuals likely approach medical decisions pertaining to their own care (i.e. medical decision situations assessed by the API) differently from those pertaining to someone else (i.e. a surrogate decisionmaking situation). 
Table of Contents

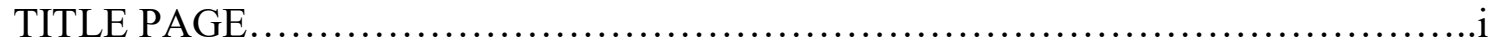

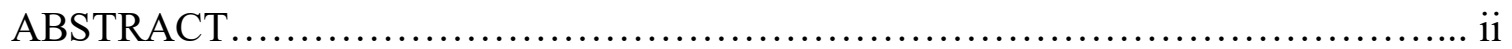

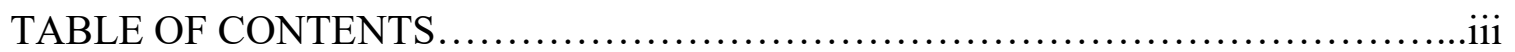

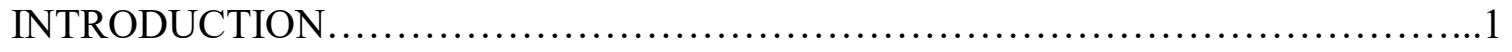

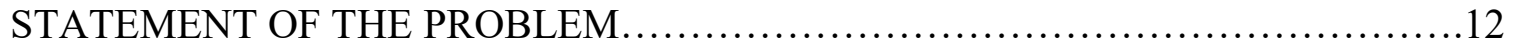

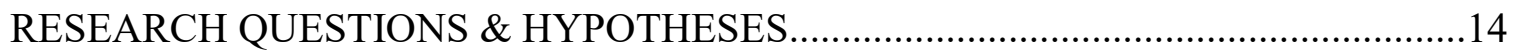

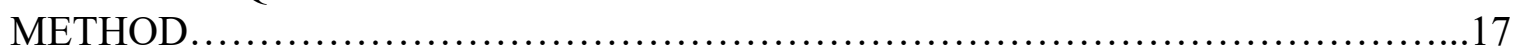

Participants \& Recruitment............................................... 17

Materials............................................................. 18

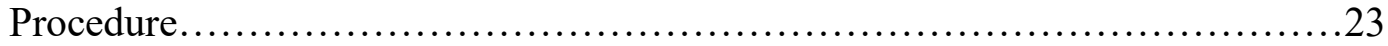

RESULTS

Demographic Characteristics..........................................24

Overview of Surrogate Decision-Making Characteristics....................... 25

Assumptions for Statistical Analyses.......................................25

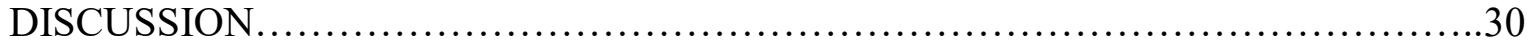

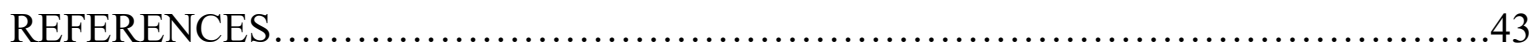

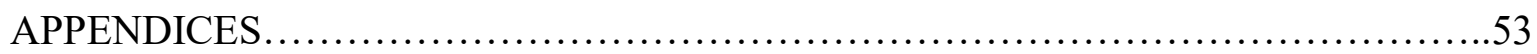

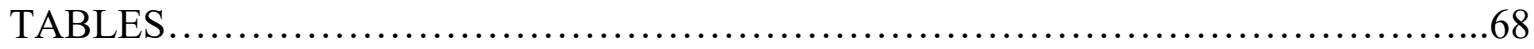


Recent health care advances have innovated numerous end-of-life care options, with measures that can extend life or enhance patient comfort. End-of-life care broadly describes the support given to a patient at or before the time of his or her death. Individuals suffering from chronic or terminal illnesses may receive end-of-life care for an extended amount of time, while patients whose death is more sudden may receive such care for a shorter period. Decisions about end-of-life care can include determining entrance into hospice or palliative care programs as well as resuscitative medical interventions or life support/ventilation. (National Institute on Aging, 2017).

Patients can express their end-of-life care preferences through various forms and documentation. A legal representative can assist a patient with preparing an advance directive. This document provides treatment guidelines for doctors and family members to follow in the event that patients later becomes unable to make such decisions for themselves. There are two main types of advance directives. First, a living will indicates specific treatments that patients do or do not want provided for them, including resuscitation and life support interventions. Second, a durable power of attorney for health care allows patients to name an individual whom they would like to make medical decisions on their behalf (Patient's Rights Council, 2013). For patients, completing advance directives encourages conversations with healthcare providers in order to improve patient control over the type of end-of-life care they receive. However, it is unclear whether these documents actually have a meaningful impact, as the patient outcome data are equivocal. Some studies indicate that completion of an advance directive increases the likelihood that a patient will receive his or her preferred care at end-of-life (Bischoff, Sudore, Miao, Boscardin, \& Smith, 2013; Silveira, Kim, \& Langa, 2010). In contrast, a recent study suggests that preferences stated in advance directives are not always honored. Silveira et al. 
(2014) found that completion of an advance directive was unrelated to the fulfillment of desires for non-hospitalized death among a large representative sample of American patients.

An attempt to correct the potential problems associated with adherence to advance directives has emerged through another document: the Physician Orders for Scope of Treatment (POST). The document is not intended to replace advance directives, but may be used concurrently or with seriously ill patients who do not have an advance directive in place. The POST seeks to clearly operationalize patient preferences for certain end-of-life decisions in a medical order that can be understood and respected by all medical professionals. It is recommended that physicians complete a POST document with all patients whose remaining life expectancy is less than 12 months (West Virginia Center for End-of-life Care, 2016). This includes seriously ill individuals who have been diagnosed with a life-limiting progressive disease and individuals who are considered to be very frail. The POST is part of the Physician Orders for Life-Sustaining Treatment (POLST) Paradigm Program, which was designed to improve health care systems' sensitivity to a full spectrum of patient preferences (Hickman et al., 2009). POST forms are currently the standard preferred method of end-of-life care planning in three states (California, Oregon, and West Virginia), while 43 states have adopted approved POST forms in some capacity or are in the process of developing these programs (National POLST Paradigm, 2016). The POST acts as a medical order that is completed in advance to ensure that patient preferences are clearly operationalized in a manner that can be understood and respected by all medical professionals.

While each state has the flexibility to create its own version of the POST, the form generally incorporates three sections. The first section expresses a patient's preferences regarding cardiopulmonary resuscitation ("Resuscitate" or "Do Not Resuscitate"). The second section 
prompts the patient to select the preferred "level of care" they wish to receive. This is often expressed through three levels: Comfort Measures (Use medication to relieve pain and suffering; keep comfortable; avoid hospital transfers and life-sustaining treatment), Limited Additional Interventions (Use comfort measures in addition to medical treatment, antibiotics, IV fluids, and cardiac monitoring as indicated; transfer to hospital if needed; avoid intubation, mechanical ventilation, or intensive care units), and Full Intervention (Use all previously described care in addition to intubation, mechanical ventilation, advanced airway interventions, or cardioversion; allow hospital transfers and intensive care units). The third section indicates preferences for medically administered fluids and nutrition (No IV fluids, IV fluids for specified trial period, IV fluids long-term; No feeding tube, Feeding tube for specified trial period, Feeding tube longterm). Physicians consult with the patient to denote preferences for each of these decisions on the POST form. Decisions on the POST form are therefore expressed as a formal physician order.

If a patient becomes temporarily or permanently unable to adequately express his or her wishes, another individual may be consulted to make decisions or complete a form such as the POST that denotes treatment preferences. This is particularly common in end-of-life situations, as nearly $50 \%$ of patients fail to meet criteria for decision-making capacity at end-of-life (Tejwani et al., 2013). According to Leo (1999), input from this surrogate decision-maker (hereafter referred to as a "surrogate") is sought when a patient is determined to lack decisionmaking capacity and a treatment decision needs to be made, a situation which typically occurs near the end of the patient's life. If a patient has explicitly stated his or her preferences for a specific treatment situation in an advance directive, these wishes will be followed. However, if preferences for a particular situation are not expressed in the advance directive or no such document exists, a surrogate will need to be consulted. This surrogate is often identified through 
a patient's durable power of attorney for medical decisions. The power of attorney is a written authorization that enables someone identified by the patient to make decisions on his or her behalf. If no such person is identified, or the person identified is unwilling to serve in the role, the patient's physician will appoint an adult over age 18 from the patient's family or an available public guardian. In the event that a surrogate is appointed for a patient, many states have established a "hierarchy" of relatives that should be consulted (e.g. adult spouse, adult child, parent, adult sibling, etc.). If the selected surrogate is not related to the patient, the surrogate may not be the patient's treating health care provider or an employee of the patient's healthcare facility (Appalachian Legal Services, 2000). In the absence of an advance directive or a similar document that explicitly states a patient's treatment preferences, a surrogate is expected to make decisions using the standard of substituted judgment; that is, decide based on what the patient would have chosen if the patient was capable (Torke, Alexander, \& Lantos, 2008).

Unfortunately, surrogate decision makers often make decisions that poorly reflect patients' wishes. In a study comparing patients' end-of-life care preferences with those predicted by their surrogates, Marks and Arkes (2008) found that surrogates showed a strong tendency to project their own desires and opinions onto their predictions for the patient. That is, surrogates often mistakenly responded with what they would want the patient to choose, rather than the patient's actual preference. This tendency to project one's own desires when making decisions for others has been replicated in other work (e.g. Bryce et al., 2004; Fagerlin, Ditto, Danks, \& Houts, 2001). In qualitative interviews with surrogates, Vig et al. (2006) found that some surrogates carry out their role in accordance with their own beliefs and definitions of an acceptable quality of life. Such findings have raised concern regarding the judgment of surrogate decision makers. A systematic literature review by Shalowitz, Garrett-Mayer, and Wendler 
(2006) regarding surrogates' accuracy when asked to make decisions for patients found that onethird of all assessed cases featured surrogates incorrectly predicting patient preferences.

These alarming conclusions have prompted further investigation to better understand the process by which surrogates make decisions and factors related to the quality of their decisions. For example, researchers (e.g. Gries, Curtis, \& Wall, 2008; Limerick, 2007) have found that surrogates who have more contact with the patient's healthcare providers and receive more information regarding his or her medical care report greater confidence in their decisions and make higher-quality decisions. Also, surrogates who have limited or no prior discussions with the patient regarding treatment preferences generally report lower confidence in their ability to fulfill decision-making obligations (Majesko, Hong, Weissfeld, \& White, 2012).

Surrogates may collaborate with patients' healthcare providers to gain additional information and input prior to making a decision. Collaboration in medical decision settings has mostly been researched in the context of patient-physician collaboration. In light of the emphasis now placed on the benefits of shared decision making (Spatz, Krumholz, \& Moulton, 2016), patient-physician collaboration has become a focus such that the Informed Medical Decisions Foundation now defines shared decision making as "a collaborative process that allows patients and clinicians to make health care treatment decisions together" (2012). A recent meta-analysis reveals that the majority of patients prefer sharing decisions with their physician while maintaining an active role (Chewning, Bylund, Shah, Arora, Gueguen, \& Makoul, 2012). However, surveys of patient populations indicate that patients are generally reluctant to voice disagreement with their physician and thus prefer to collaborate by mostly agreeing to physicians' suggestions (Adams, 2012). When a surrogate decision-maker attempts to make a choice on behalf of a patient, the patient is faced with similar options for participation and 
collaboration with healthcare providers. However, there has been little formal investigation of surrogate-provider collaboration thus far.

Given the lack of research on the surrogate decision-making process, findings related to self-other decision-making can potentially inform future endeavors in this area. According to the "social values" theory of self-other decision-making, individuals' willingness to make risky decisions for other people is influenced by whether risk is valued in the particular context of the decision (Stone \& Allgaier, 2008). Surrogates may choose to collaborate with others, such as the patient's healthcare providers, to inform their risk assessments of patients' situations before making a decision. The extent to which a surrogate works with a provider can have important outcomes on the decision-making process and the eventual quality of decisions, especially in light of findings that patients who collaborate with their physicians and take some responsibility for their own medical decisions tend to be better informed and more satisfied with their care (Trede \& Higgs, 2003).

Investigating the collaborative behaviors involved in surrogate decision-making also provides a novel addition to the broader decision science literature. Decision science has generally focused on the individual process of making a choice, rather than exploring decisionmaking as a social process. Prior research investigating dyadic decision-making primarily considers romantic couples' approach to decisions in three main areas: financial decisions, medical decisions, and retirement planning (Queen, Berg, \& Lowrance, 2015). When confronting medical decisions, couples appear to vary in how actively they participate in the collaborative process, with one partner often preferring to have a more passive, supportive role (Schumm, Skea, McKee, \& N'Dow, 2010). The manner in which partners choose to be involved in each other's medical decisions may indicate their acceptance with the diagnosis and its implications, 
such that those who are coping better are more willing to actively engage in collaboration (Queen et al., 2015). Investigating how non-romantic partners, such as surrogates and patients' health care providers, collaborate on medical decisions could provide an interesting comparison to these trends reported from the couples' decision-making literature.

As previously described, investigating collaborative behaviors among surrogates has significance for both the broader field of decision science and the medical decision-making literature. However, like many types of decisions, a surrogate's choice of whether to consult further with the patient's medical providers is complex and can be affected by numerous variables. In the following sections, I will describe several variables that could potentially be related to surrogates' collaborative willingness. The selection of these variables is informed by both the medical decision literature and the field of decision science.

\section{Decision-Making Confidence}

Collaborative decision-making can provide one with additional information and perspectives that in turn promote confidence in one's decision. Decision-making confidence may result from collaboration (Heath \& Gonzalez, 1995), but can also function as a predictor of collaboration preferences since more confident individuals may be less likely to consult with others prior to making a choice. Strough, Cheng, and Swenson (2002) investigated older adults' collaboration preferences across several domains of everyday problems (e.g. household problems, health, finances) and found that individuals were more likely to desire collaboration in domains where they felt personally deficient or incapable. Concerns for personal ability are relevant across age groups, as indicated by findings from Blanchard-Fields, Chen, and Norris (1997) that perceived ability (confidence) in a problem domain predicts more problem-solving strategy preferences, such that those with less confidence select more passive strategies. That is, 
individuals who have less confidence in a situation are more likely to turn to others to make decisions. This suggests that people who generally lack confidence in their ability to make a good medical decision for someone else will lean heavily upon the input of a person whom they view as more capable in this situation, like the patient's healthcare provider.

\section{Intolerance of Uncertainty}

The uncertainty surrounding medical decisions can also influence surrogates' willingness to collaborate when encountering these situations. Han (2016) describes three main sources of uncertainty in medical decisions: first, the random probability of future outcomes; second, the ambiguity of medical information, which can be inadequate or vague; third, the complexity of relevant information that can exacerbate decision-making difficulty for non-medical professionals. In particular, Han (2016) asserts that ambiguity is likely the most prominent source of uncertainty in medical decisions and motivates shared decision-making in situations where individuals feel as if they lack pertinent information and subsequently share decisionmaking with a more knowledgeable person.

Ambiguity aversion is implicated in the broader construct of intolerance of uncertainty, which refers to how people may perceive unknown outcomes as unacceptably threatening. Individuals who are highly intolerant of uncertainty are more likely to demonstrate poor decision-making strategies and to experience behavioral inhibition, resulting in longer decisional latency, during unpredictable situations (Carleton, Mulvogue, Thibodeau, McCabe, Antony, \& Asmundson, 2012; Dugas, Freeston, \& Ladouceur 1997). Intolerance of uncertainty is strongly associated with decision-making confidence, as highly intolerant individuals demonstrate reduced confidence in their decisions that worsens across multiple decision-making trials (Jensen, Kind, Morrison, \& Heimberg, 2014). 


\section{$\underline{\text { Anxiety }}$}

Intolerance of uncertainty is strongly related to anxiety, another variable which can influence individuals' collaboration preferences. Health information that is delivered to patients and their surrogates can be quite ambiguous, involving indefinite treatment outcomes or prognoses. This ambiguity prompts consideration of how anxiety might influence preferences for support-seeking behaviors such as collaboration. In general, anxiety impairs decision-making abilities, as evidenced by findings in the psychophysiological (Miu, Heilman, \& Houser, 2008) and behavioral (Greifeneder, Bless, \& Pham, 2011) literatures. Particularly in healthcare situations, Frosch and Kaplan (1999) suggest that individuals may feel pressured to make the best decision and that patients who already struggle with anxiety may be more likely to defer decision-making to their healthcare providers. For surrogates, this deferral tendency may manifest as a heavy reliance on others to bear the burden of making decisions on behalf of the patient. Those with higher levels of anxiety may also be more avoidant of potentially distressing information, such as health information and prognoses that would be conveyed in conversations with a healthcare provider (Howell \& Shepperd, 2016). This may manifest as an increased willingness to seek input from healthcare providers regarding medical decisions. Moreover, $\mathrm{Wu}$ and Gonzalez (1999) propose that the amount of time that must elapse before uncertainty can be resolved affects one's experience of the decision-making process, such that a longer temporal lapse before resolution can heighten anxiety. This may be particularly applicable in medical decision-making situations where any given choice may have delayed consequences for one's health, such as when completing documents such as advance directives that denote end-of-life care preferences.

\section{Experiential Avoidance}


Anxiety is also associated with risk-avoidant decision-making behaviors, such that anxious individuals tend to be very averse to risk (Maner et al., 2006). Risk-averse cognitive strategies appear to be composed of various dimensions of avoidance, one of which is experiential avoidance (Leahy, Tirch, \& Melwani, 2012). Experiential avoidance describes an individual's tendency to avoid distressing emotional experiences or physiological sensations (Gámez et al., 2014). The construct could be hypothesized to influence one's decision-making preferences given that decisional situations, particularly those occurring in a medical context, can provoke uncomfortable feelings of stress and uncertainty. While there is little literature to date regarding experiential avoidance and decision-making preferences, the rational-emotional decision avoidance model proposed by Anderson (2003) postulates that excessive concern for potential negative emotional experiences can prompt avoidant decisional behavior. Using this model, experiential avoidance can be considered in relation to one's willingness to collaborate or otherwise participate in decisions. Individuals with high levels of experiential avoidance may prefer to avoid a decision altogether or defer to another person rather than confront the decision directly.

\section{Consideration of Future Consequences}

Decision-avoidant behavior is particularly interesting to examine in situations involving medical treatment decisions, since even those who are more tolerant of distressing experiences may nonetheless find the ambiguity associated with healthcare decisions to be troubling (Han et al., 2011). This may be due to the fact that thinking about medical treatment decisions, such as when completing an advance directive, evokes an evaluation of the future risks and benefits associated with these choices. The degree to which individuals are comfortable with futureoriented thought may subsequently influence their comfort with being involved in healthcare 
decisions that address future treatment and potentially life-altering consequences. Futureoriented thought has been measured as a construct termed consideration of future consequences, a construct which reflects one's conceptualization and prioritization of distant and immediate outcomes (Strathman, Gleicher, Boninger, \& Edwards, 1994). Individuals who score high on measures of consideration of future consequences tend to consider the future implications of their behaviors and decisions more heavily than those who score low on the construct. In investigations of considerations of future consequences and health behaviors, those who score highly in the construct appear to be more receptive to health-promoting messages and more likely to engage in health-related behaviors because they are able to consider the long-term consequences of their health behaviors (Joireman, Shaffer, Balliet, \& Strathman, 2012; Orbell, Perugini, \& Rakow, 2004). Since consideration of future consequences appears to be associated with increased sensitivity to healthcare communications that direct recipients to long-term consequences, individuals who score highly on measures of the construct may be more likely to seek out or consider information conveyed by physicians pertaining to healthcare decisions.

When considering variables that may affect the degree to which surrogates seek out additional input from others, it is important to note how individuals may approach decisionmaking for others differently than decision-making for the self. One variable that the broader decision-making literature has investigated in relation to self-other decision making is risktaking. Investigations of general self-other differences in decision making have helped discern whether people take more risks when deciding for another person versus for themselves. A "social values" view of self-other decision-making has gained favor in the field, positing that people make riskier decisions for other people in situations where risk is valued (i.e. going on a date with someone new) (Stone \& Allgaier, 2008). To gain information that can inform such risk 
assessments of a patient's situation, the surrogate may choose to collaborate with others (e.g. physicians, family members) prior to making a decision. While collaboration is a tool that is available to both surrogates and the patients they serve, prior research on collaboration preferences in health-care settings have primarily focused on the perspective of the patient as the collaborator (Strough, Cheng, and Swenson, 2002).

\section{Statement of the Problem}

Most people will receive end-of-life care at some point. The patient-centered care movement has encouraged shared decision-making among the medical community, particularly on decisions related to end-of-life care. Researchers (Adams, 2012; Chewning, Bylund, Shah, Arora, Gueguen, \& Makoul, 2012) have investigated the extent to which patients prefer to make these important medical decisions independently or with the guidance of their healthcare providers. Individuals can express their preferences for end-of-life care through various types of advance directives. Recently, states have begun to adopt a new type of advance directive known as the POST (Physician Order for Scope of Treatment), a formal physician order that travels with a patient's medical record and outlines one's preferences for end-of-life care. The POST requires collaboration between the medical professional and decision-maker. It is currently in use or under development in nearly all 50 states (National POLST Paradigm, 2016). Little to no research has explicitly investigated decision-making with respect to the POST form.

Decisions about end-of-life care, such as those made on the POST form, are often made by surrogate decision makers when patients become incapable of making such decisions for themselves, a situation which frequently occurs at end-of-life. Despite the fact that surrogates are often responsible for making these important decisions, virtually nothing is known about the surrogate decision-making process or factors relating to surrogates' decision-making preferences. 
A greater understanding of these processes and factors would allow healthcare providers to be better informed when working with surrogates, promoting their ability to more effectively inform, support, and communicate with these individuals throughout the decision-making process.

Since collaboration is an essential element of the completion of the POST form, the willingness of the decision maker to collaborate and seek personal involvement in the decisionmaking process is particularly relevant. Findings from the shared decision-making literature indicate that characteristics of both the patient and healthcare provider can function as barriers and facilitators to collaborative decision-making (Bunn et al., 2018; Joseph-William, Elwyn, \& Edwards, 2013). Thus, the current study investigated the ability of several psychological characteristics to predict willingness of hypothetical surrogate decision makers to seek personal involvement in medical decisions and collaborate with healthcare providers on decisions associated with the POST. Personal involvement was considered as the extent to which respondents wanted to make decisions themselves, as opposed to letting the physician take complete control of the decision. The psychological characteristics selected for examination were drawn from the literature due to their demonstrated relations to collaborative decision-making, and include the following: intolerance of uncertainty, experiential avoidance, anxiety, consideration of future consequences, and decision-making confidence. These psychological characteristics were first examined for their ability to predict one's willingness to seek personal involvement in medical decisions and collaborate with healthcare providers across the POST decisions. The variables' predictive ability was then also examined for each of the three POST decisions individually. 
For exploratory purposes, a series of demographic variables were also evaluated for their ability to predict collaborative willingness. These variables included race/ethnicity, age, gender, years of education, and marital status.

\section{Research Questions and Hypotheses}

Research Question \#1: Will confidence in one's decisions contribute to the prediction of one's willingness to collaborate with healthcare provider or seek personal involvement on medical decisions?

Hypothesis \#1: Total decision-making confidence scores across the three POST decisions will contribute to the prediction of one's willingness to collaborate and seek personal involvement in medical decisions. This hypothesis is based on findings that confidence in one's ability in a given domain predicts the problem-solving strategies that individuals choose (Blanchard-Fields et al., 1997; Strough et al., 2002). Findings from this problem-solving literature reveal that individuals who feel more confident in their abilities in a given problem domain are less likely to collaborate with others who may not share their expertise. Findings for the current study are hypothesized to be more consistent with those reported in the shared decision-making literature that patients with greater confidence in their abilities to meaningful contribute to a decision are more likely to participate in shared decision-making with their physicians (Joseph-Williams et al., 2013). Thus, greater confidence will be associated with greater desire for collaboration and personal involvement.

Research Question \#2: Will intolerance of uncertainty predict willingness to collaborate with healthcare providers and seek personal involvement in medical decisions?

Hypothesis \#2: Scores on a measure of intolerance of uncertainty will contribute to the prediction of one's willingness to collaborate and seek personal involvement in medical 
decisions. Greater intolerance of uncertainty will be associated with less desire for active collaboration and heavy personal involvement. This hypothesis is based on findings that individuals who are highly intolerant of uncertainty tend to struggle with decision-making in general, make poorer decisions, and feel less secure in their decisional ability (Dugas et al., 1997; Carleton et al., 2012).

Research Question \#3: Will levels of anxiety predict willingness to collaborate with healthcare providers and seek personal involvement in medical decisions?

Hypothesis \#3: Scores on a trait-level measure of anxiety will contribute to the prediction of one's willingness to collaborate and seek personal involvement in medical decisions. Greater anxiety will be associated with less desire for active collaboration and personal involvement. This hypothesis is based on findings that anxious individuals tend to struggle with medical decisions and may be more likely to defer decision-making to healthcare providers, as these high-stakes decisional situations present distressing information that they would rather avoid (Frosch \& Kaplan, 1999; Howell \& Shepperd, 2016).

Research Question \#4: Will consideration of future consequences predict willingness to collaborate with healthcare providers and seek personal involvement in medical decisions?

Hypothesis \#4: Scores on a measure of consideration of future consequences will contribute to the prediction of one's willingness to collaborate and seek personal involvement in medical decisions. Specifically, greater consideration to future consequences will be associated with greater desire for actively collaboration and personal involvement. This hypothesis is based on findings that consideration of future consequences is strongly associated with receptivity to 
health information and engagement in health behaviors (Joireman, Shaffer, Balliet, \& Strathman, 2012; Orbell, Perugini, \& Rakow, 2004).

Exploratory Research Question \#1: Will experiential avoidance predict willingness to collaborate with healthcare providers and seek personal involvement on medical decisions?

Exploratory Research Question \#2: Will the following psychological characteristics (intolerance of uncertainty, anxiety, consideration of future consequences, decision-making confidence, and experiential avoidance) predict willingness to collaborate and seek personal involvement in medical decisions for the CPR-related POST decision scenario?

Exploratory Research Question \#3: Will the psychological characteristics predict willingness to collaborate and seek personal involvement in medical decisions for the levels of care-related POST decision scenario?

Exploratory Research Question \#4: Will the psychological characteristics predict willingness to collaborate and seek personal involvement in medical decisions for the fluids and nutrition-related POST decision scenario?

Exploratory Research Question \#5: Which of the following demographic variables will predict total collaborative willingness scores on the three POST decisions: age, gender, marital status, race/ethnicity, and years of education?

\section{Participants and Recruitment}

\section{Method}

Appropriate exclusion criteria were applied to exclude individuals who were under age 18 or who had previously served in a formal surrogate decision-making capacity. Rather than 
recruiting individuals who currently serve as surrogates, recruitment was open to all individuals who met the inclusion criteria based on the logic that any individual may be called upon to act as a surrogate at some point in the future. Assessing the attitudes of a community-dwelling sample is meaningful for understanding how individuals would approach these decisions at a later point in time. Furthermore, it was important that the recruited sample did not have experience with making medical decisions for others in a formal capacity. This was informed by findings that individuals who have served as a healthcare surrogate and have more experience with the role report greater confidence and ease with the process relative to those with less experience (Majesko et al., 2012). By ensuring that all participants had similar levels of personal familiarity with the surrogate decision-making role, the possibility of any confounding effects due to experience was attenuated.

A total of 510 responses were obtained from individuals who responded to an online survey advertisement on Amazon Mechanical Turk. Respondents who indicated that they were less than 18 years old $(N=1)$ or had prior experience serving in a formal surrogate decisionmaking capacity $(N=327)$ were excluded. Following the application of exclusion criteria, 10 more responses were excluded due to failure to accurately respond to at least one of the three validity check items (e.g. "Please select "somewhat uncertain") in the survey. A final sample of 172 respondents remained, aged 20 to 69 years $(M=49$ years, $S D=15.05$ years). All respondents resided in the United States.

\section{Materials}

Demographic questionnaire. All participants completed a demographic questionnaire to begin the survey. Questions included age, gender, ethnicity/race, marital status, and years of education. At this time, participants were asked if they had ever served as a surrogate decision- 
maker, phrased as "a situation in which you were asked by a doctor to make an important medical decision on behalf of another adult (such as a spouse, parent, sibling, adult child, or close friend)." In accordance with the previously described exclusion criteria, respondents who indicated "Yes" to this question were not permitted to proceed with the survey. Participants also indicated whether they have ever served in a less formal decision-making capacity, phrased as a situation in which "you were involved in making a medical decision for another adult." Participants then rated, on a 4-point Likert-type scale, their willingness to serve as a surrogate decision-maker, phrased as "a position where you may be asked to make important medical decisions on behalf of another adult (such as a spouse, parent, sibling, adult child, or close friend)." To explore the social norms surrounding collaborative decision-making, participants also used a 4-point Likert-type scale to indicate the extent to which they thought people typically collaborate with their healthcare providers on medical decisions. The demographic questionnaire is presented in Appendix A.

Instruction form. Eligible participants viewed and completed an instruction form that informed them that the following task would ask them to make hypothetical medical decisions for someone else in an imagined surrogate decision-making situation. In an attempt to reduce variability in the health status of the imagined patient, participants were informed that doctors have estimated that the patient has less than one year to live. Participants then "nominated" an adult from their life who they would consider when making these decisions. Participants indicated their relationship to this person (e.g. parent, spouse, etc.) and the degree to which they liked the individual. Participants also rated the extent to which they had discussed end-of-life decisions with this person, including his or her personal preferences. Finally, participants indicated whether this person has an advance directive (“I don't know" was presented as an 
option) and if they knew what this advance directive says. The instruction form is presented in Appendix B.

Decision prompts. A series of hypothetical decision prompts simulated the three sections of the POST form (indicating preferences for: CPR, levels of care, artificial fluids and nutrition; see Appendix C). The decision prompts were presented in the order they appear on the West Virginia POST form using a vignette style modeled from Hare, Pratt, and Nelson (1992). The prompts first explained the type of intervention (e.g. defining "CPR" or describing the "levels of care" options) and then asked participants to indicate the option that they would choose if asked to decide on behalf of the person they selected.

Following each of the three decision prompts, participants answered two items. First, they used a 5-point Likert-type scale to rate their level of confidence in making the preceding decision, thus allowing for a total confidence score to be obtained across all three POST decisions. Respondents also used the same 5-point Likert-type scale to indicate degree of confidence that the decision they made is what the patient would want. Next, they rated on a 5point Likert-type scale the extent to which they would be willing to collaborate with the nominee's healthcare provider(s) on the decision. These ratings of collaborative willingness were used to calculate a total collaborative willingness score across all three POST decisions. "Collaboration" was defined in the item as "the act of working with others to reach a shared decision or goal." Following the decision prompts, respondents further indicated how they considered "collaboration" by using a 5-point Likert-type scale to indicate both their willingness to defer decisional responsibility to another individual (e.g. the patient's healthcare provider) and their willingness to accept full responsibility for the decision. Respondents also selected from a 
list of options what they would hope to gain from such collaboration (e.g., emotional support, more information regarding the patient's condition).

Intolerance of Uncertainty Scale—short version (IUS; Carleton, Norton, \& Asmundson, 2007). The IUS is a 12-item self-report measure of intolerance of uncertainty, included in Appendix F. Respondents indicate the degree to which each statement describes them on a 5point Likert-type scale ranging from 0 (not at all characteristic of me) to 5 (very characteristic of me). Scores range from 0 to 60 , with higher scores indicating greater intolerance of uncertainty. This shortened version of the original Intolerance of Uncertainty Scale (Freeston, Rhéaume, Letarte, Dugas, \& Ladouceur, 1994) demonstrates strong psychometric properties, with high internal consistency reliability ( $\alpha=.94)$ and strong convergent validity evidence with related measures of anxiety, such as the Beck Anxiety Inventory and the Penn State Worry Questionnaire; validity coefficients range from .57 -.64 (Carleton et al., 2007). The internal consistency estimate was good for the current sample: $\alpha=.94$.

State-Trait Anxiety Inventory-Trait Subscale (STAI-T; Speilberger, 1983). The STAI-T is a 20 -item instrument that measures the respondent's propensity to experience anxiety and perceive situations as threatening. Respondents indicate the degree to which each statement is true of themselves, in general, on a 4-point Likert-type scale ranging from 0 (not at all) to 4 (very much so). Scores range from 0 to 80 , with higher scores indicating greater levels of trait-level anxiety. The measure has high test-retest reliability, ranging from $.73-86$. Strong concurrent validity evidence with other measures of anxiety has been reported, ranging from $.73-.85$ (Speilberger, 1983). Good internal consistency was demonstrated among the current sample, $\alpha=$ 91. 
Consideration of Future Consequences Scale (CFC; Strathman, Gleicher, Boninger, \& Edwards, 1994). The CFC is a 12 -item measure designed to measure the degree to which respondents consider future consequences in their everyday life, included in Appendix G. Respondents indicate the degree to which each statement describes them on a 5-point Likert-type scale ranging from 0 (extremely uncharacteristic) to 5 (extremely characteristic). Scores range from 0 to 60 , with higher scores indicating greater consideration of future consequences. The measure has strong psychometric evidence, including good internal consistency reliability ( $\alpha$ $=.82)$ and test-retest reliability $(r=.76, p<.001)$. Validity evidence includes moderate relations with other measures of future orientation, with validity coefficients ranging from $.43-.47$ (Strathman et al., 1994). Internal consistency was acceptable among the current sample: $\alpha=.77$. Brief Experiential Avoidance Questionnaire (BEAQ; Gámez, Chmielewski, Kotov, Ruggero, Suzuki, \& Watson, 2014). The BEAQ is a 15 -item shortened version of the Multidimensional Experiential Avoidance Scale (Gámez et al., 2011), included in Appendix H. The measure assesses experiential avoidance, or the degree to which respondents avoid prolonged contact with distressing emotional experiences and physical sensations. Respondents indicate their level of agreement with each of the items on a 6-point Likert-type scale ranging from 0 (strongly disagree) to 6 (strongly agree). Scores range from 0 to 90 , with higher scores indicating greater levels of experiential avoidance. Strong psychometric evidence supports the use of the instrument, including high internal consistency reliability (ranging from $.80-.86$ ) and strong convergent validity evidence with other measures of experiential avoidance; validity coefficients ranging from $.54-.64$. Good internal consistency was demonstrated among the current sample, $\alpha=.92$. 
Autonomy Preference Index — decision-making subscale (API; Ende, Kazis, Ash, \& Moskowitz, 1989). The decision-making subscale of the API measures the extent to which the respondent would want a physician to assume complete control over various medical decisions. The subscale features two components, included in Appendix I. The first component assesses general medical decision-making preferences. Respondents indicate their level of agreement with six statements regarding patient-physician control over treatment decisions. Respondents use a five-point Likert scale ranging from 0 (strongly disagree) to 5 (strongly agree). Three items on this subscale were reverse-scored, such that higher scores indicated preferences for greater involvement in medical decisions; see Appendix J. Scores on this component therefore range from 0 to 30 .

The second component of the subscale is a decision scenario subset that asks individuals to respond to three vignettes. Each vignette asks respondents to imagine that they are experiencing symptoms or a condition that requires a medical decision to be made. Three potential decisions follow each vignette; thus, participants view a total of nine hypothetical decisions. Respondents rate each decision on a five-point Likert-type scale describing the extent to which the patient and physician should share the decision $(1=$ you [the patient] alone should make the decision, 3 = both share the decision equally, $5=$ the doctor alone should make the decision). Items on the decision scenario subset are reverse-scored, such that higher scores indicate preferences for greater involvement in medical decisions. Scores on this component therefore range from 0 to 45 , with higher scores indicating stronger preferences for personal involvement and autonomy in medical decisions.

Acceptable internal consistency reliability $(\alpha=.82)$ and test-retest reliability $(\alpha=.84)$ have been demonstrated for the 6-item decision-making preference component of the subscale 
(Simon, Kriston, Loh, Spies, Scheibler, Wills, \& Härter, 2010). Internal consistency for this component among the current sample was acceptable, $\alpha=.77$. Internal consistency for the decision scenario component of the subscale was also acceptable, $\alpha=.79$.

\section{Procedure}

A procedure flow chart is provided in Appendix D. Participants were recruited online through Amazon Mechanical Turk (MTurk) and completed all survey measures through Qualtrics, an online survey platform. Participants read a brief informational page describing the study and indicated their consent by proceeding to the next page of the survey. Recruitment practices were approved by the West Virginia University Institutional Review Board. All participants completed all questionnaires. The demographic questionnaire was presented first, followed by the instruction sheet and the decision prompts. The remaining measures were presented in a random order to minimize potential order effects.

To check for valid age reporting, participants were asked to provide their year of birth at the end of the survey. The demographic questionnaire at the beginning of the survey required participants to report their age in years. Consistency between age and year of birth was examined (i.e., whether age and birth year matched within 1 year) and data of individuals with inconsistent responses were not included in the final data set. Three general validity items were also randomly distributed throughout the survey and prompted respondents to indicate that they had thoroughly read the item by selecting a certain response (e.g. "Please select 'somewhat agree"'). Responses from participants who provided incorrect answers to more than one of these items were not included in the final data set. 
At the conclusion of the survey, participants received a code to use to confirm participation and obtain payment through MTurk. Participants were compensated $\$ 1$ for their participation.

\section{Handling of Missing Data}

Overall, $3.2 \%$ of the values for all items were missing, meeting the minimal missingness criterion (less than 5\%) for use of simple imputation, according to Field (2013). If a respondent skipped an entire measure (e.g. the IUS, the POST decision prompts, etc.) or otherwise did not respond to more than $25 \%$ of the questions across the entire survey, their responses were excluded from all analyses. Simple imputation was used for missing data that was not excluded whereby the sample mean for the measure was imputed for the missing item. A total of 172 responses were included in the final analyses.

Results

\section{Demographic Characteristics}

Demographic information for the sample appears in Table 1. Research supports the use of MTurk to obtain high-quality data and indicates that samples recruited with this method may be more demographically diverse than traditional internet samples or college student samples (Buhrmester, Kwang, \& Gosling, 2011; Goodman, Cryder, \& Cheema, 2013). In general, more men than women participated (62\% and $38 \%$ of the sample, respectively), which is not unusual for web-based research (Gosling, Vazire, Srivastava, \& John, 2004). With regard to race and ethnicity, a fairly diverse sample was recruited in proportions generally representative of 2017 US Census. However, the proportion of individuals identifying as Hispanic likely underrepresents the true United States population. According to 2017 US Census data, $18.1 \%$ of the population identifies as Hispanic or Latino, while only $4.7 \%$ of the current sample identified as 
such (United States Census, 2017; see Table 1). Categorical demographic variables with more than two groups (race and marital status) were recoded into dummy variables for use in the later regression analyses. No participants identified as a gender other than male or female, so dummy coding was not used for the gender variable.

\section{Overview of Surrogate Decision-Making Characteristics}

For the activity in which participants chose an individual from their life to imagine in a series of hypothetical surrogate decision-making scenarios, $27.9 \%$ selected a parent, $34.3 \%$ selected a spouse, $11.0 \%$ selected a sibling, 5.8\% selected an adult child, $5.8 \%$ selected a grandparent, $2.9 \%$ selected another family member, and $12.2 \%$ selected a close friend. When asked if the person they selected had an advance directive, $34.3 \%$ of respondents indicated that they did not know, whereas $33.7 \%$ indicated "no" and $32.0 \%$ indicated "yes." Of those who responded that the person they selected had an advance directive, $87.3 \%$ indicated that they knew the person's preferences as detailed in the document. While none of the participants had ever served in a formal surrogate decision-making capacity, $64.5 \%$ indicated that they had previously given advice to another adult concerning a major medical decision.

Descriptive statistics for additional questions related to participant characteristics as hypothetical surrogate decision makers appear in Table 3. Note that respondents utilized the same 4-point Likert-type scale for these items, ranging from " $1=$ not at all" to " $4=$ very much."

\section{Descriptive Statistics}

Descriptive statistics, including means and standard deviations, for the predictor and criterion variables are presented in Table 2. The distribution of scores for the sample was consistent with trends reported in research with similar samples. 
An examination of histograms and scatter plots revealed no need to transform data or exclude outliers. For all measures, skew and kurtosis values were acceptable, well below a criterion value of 1 . Correlations between all predictor and criterion measures were examined (see Table 4), indicating significant correlations between many of the variables. However, none of the correlations among psychological characteristics exceeded the .80 cutoff suggested by Field (2013) to determine whether multicollinearity poses a significant issue.

The four assumptions of multiple linear regression analysis outlined by Kelley and Maxwell (2008) were considered: (1) normal distribution of error, (2) homoscedasticity, or homogeneity of variance across psychological characteristics, (3) independence of observations, and (4) additivity and linearity between predictor and outcome variables. Graphical representations and statistical analyses of the data were examined. A conditioning plot confirmed linearity between predictors and a p-p plot supported the assumption of homogeneity of variance.

Multicollinearity diagnostics were closely examined in the regression analyses that follow. For all analyses, tolerance values for psychological characteristics were all acceptably high, exceeding the .10 minimum level of tolerance recommended by Tabachnik and Fidell (2001). None of the variance inflation factors for any of the psychological characteristics were excessively high or exceeded the 4.0 cutoff suggested by Field (2013). Condition indices all fell below the cutoff of 30 suggested by Field (2013). In all regression analyses, eigenvalues were fairly close to zero (ranging from .005-.006). Examination of a correlation matrix (see Table 4) indicated minor intercorrelation between predictors, particularly between experiential avoidance and intolerance of uncertainty. However, some intercorrelation may be expected given the overlapping nature of these constructs. 


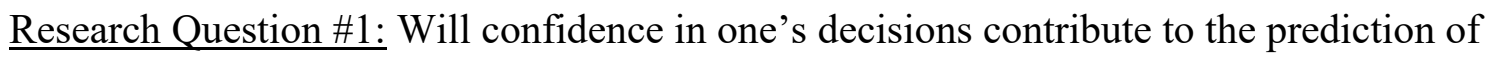
one's willingness to collaborate with healthcare provider or seek personal involvement on medical decisions?

Research Question \#2: Will intolerance of uncertainty predict willingness to collaborate with healthcare providers and seek personal involvement in medical decisions?

Research Question \#3: Will levels of anxiety predict willingness to collaborate with healthcare providers and seek personal involvement in medical decisions?

Research Question \#4: Will consideration of future consequences predict willingness to collaborate with healthcare providers and seek personal involvement in medical decisions?

Exploratory Research Question \#1: Will experiential avoidance predict willingness to collaborate with healthcare providers and seek personal involvement on medical decisions?

A series of multiple linear regression analyses were conducted to address these research questions. See Appendix E for a visual illustration of the regression model.

First, a regression analysis determined the total contribution of all five psychological characteristics (intolerance of uncertainty, experiential avoidance, anxiety, consideration of future consequences, and total confidence scores across POST decisions) to the prediction of total collaborative willingness scores. A significant regression equation was found, $F(5,165)=$ $6.04, p<.001$, and the model accounted for $15.5 \%$ of the variance in collaborative willingness. Each of the psychological characteristics was hypothesized to contribute to the prediction of total collaborative willingness. However, only confidence in POST decisions uniquely contributed, $\beta$ $=.30, p<.001$. Greater confidence predicted greater collaborative willingness, supporting the hypothesis regarding this psychological characteristic. See Table 4 for information regarding the hypothesized directional relations between the predictor variables and collaborative willingness. 
Only anxiety, decision-making confidence, and consideration of future consequences

demonstrated correlations in the hypothesized directions, such that greater anxiety was associated with less collaborative willingness and greater confidence and consideration of future consequences was associated with greater collaborative willingness.

Another regression analysis examined the total contribution of all five psychological characteristics to the prediction of total scores on the six-item general decision-making preference subscale of the Autonomy Preference Index. Higher scores on this subscale indicated greater preferences for personal involvement and control of medical decisions. A significant regression equation was found, $F(5,165)=22.96, p<.005$, accounting for over $40 \%$ of the variance. Four of the five psychological characteristics uniquely contributed to the variance in scores on the decision-making preference subscale: confidence $(\beta=-.30, p=.007)$, experiential avoidance $(\beta=.16, p=.000)$, consideration of future consequences $(\beta=-.17, p=.000)$, and anxiety $(\beta=-.07, p<.05)$. Of the psychological characteristics, only the predictive roles of consideration of future consequences and anxiety were in the hypothesized direction.

Finally, nine regression analyses were performed to determine whether the psychological characteristics contributed to the prediction of scores on the decision scenario subset of the Autonomy Preference Index. Higher scores on the decision scenarios indicated a greater desire for personal involvement and control of the decision. The five psychological characteristics (experiential avoidance, decision-making confidence, consideration of future consequences, anxiety, and intolerance of uncertainty) were used to predict the scores for each decision scenario. The model contributed significantly to the prediction of personal involvement preferences for seven of the nine decision scenarios. Results for these multiple regression analyses can be found in Table 5. Each of the psychological characteristics was hypothesized to 
contribute to the prediction of desired personal involvement in medical decisions. Only experiential avoidance contributed significantly in situations that described treatment for the common cold and routine blood pressure assessments. However, in the decision scenario describing hospitalization for a heart condition, consideration of future consequences and confidence were significant contributors.

Exploratory Research Question \#2: Will the following psychological characteristics (intolerance of uncertainty, anxiety, consideration of future consequences, decision-making confidence, and experiential avoidance) predict willingness to collaborate and seek personal involvement in medical decisions for the CPR-related POST decision scenario?

Exploratory Research Question \#3: Will the psychological characteristics predict willingness to collaborate and seek personal involvement in medical decisions for the levels of care-related POST decision scenario?

Exploratory Research Question \#4: Will the psychological characteristics predict willingness to collaborate and seek personal involvement in medical decisions for the fluids and nutrition-related POST decision scenario?

A series of multiple linear regression analyses addressed these exploratory research questions. The same five psychological characteristics (intolerance of uncertainty, anxiety, experiential avoidance, consideration of future consequences, and confidence) were used. For the regression analysis that addressed this aim, confidence scores pertaining to each specific POST decision were used instead of total confidence scores across all three POST decisions (e.g., for the CPR-related POST decision, only confidence ratings given for the CPR-related decision were used in the model). Taken altogether, the five psychological characteristics contributed significantly to the prediction of collaborative willingness for the CPR-related decision, $F(5$, 
$166)=11.93, p<.001$, accounting for $26.4 \%$ of the variance. Confidence in this CPR-related decision was the only variable that contributed uniquely to the variance, $\beta=.40, p=.000$. The model did not significantly predict collaborative willingness ratings for the other two POST decisions, related to levels of care and artificial fluids/nutrition.

Exploratory Research Question \#5: Which of the following demographic variables will predict total collaborative willingness scores on the three POST decisions: age, gender, marital status, race/ethnicity, and years of education?

A multiple linear regression analysis, including the dummy coded categorical demographic variables, revealed that only gender significantly contributed to the variance in total collaborative willingness scores, $F(1,169)=5.22, p<.05$. A one-way ANOVA indicated that females were significantly more collaborative across the decision tasks than males, $F(1,169)=$ $5.22, p<.05$. No significant differences in collaborative willingness by race/ethnicity, marital status, or years of education were evident, nor did these demographic variables appear as significant predictors of total collaborative willingness scores.

\section{Discussion}

The primary goal of the current study was to investigate the extent to which various psychological characteristics contributed to the prediction of participants' willingness to collaborate with healthcare providers (measured by total collaborative willingness scores across the three POST decisions) or seek personal involvement (measured by the Autonomy Preference Index) in medical decisions. The psychological characteristics included experiential avoidance, decision-making confidence, anxiety, intolerance of uncertainty, and consideration of future consequences. The medical decisions were drawn from the three sections of the West Virginia POST form. 
Of the psychological characteristics, only decision-making confidence contributed uniquely to the prediction of total collaborative willingness scores across the POST decision scenarios. This result supported the hypothesis regarding the predictive contribution of decisionmaking confidence. The direction of this finding, indicating that those with greater confidence are more willing to collaborate, is inconsistent with those from collaborative problem-solving investigations that show an association between greater confidence and less willingness to collaborate to solve problems (Blanchard-Fields et al., 1997; Strough et al., 2002). This discrepancy may be attributed to the difference between collaborative problem-solving and collaborative medical decision-making. In a problem-solving situation, a person who is confident in their ability to solve problems may find it cumbersome or arduous to receive help from another person who may or may not possess valuable knowledge. However, in the context of collaborative medical decision-making, individuals face a situation that is likely quite novel to them, and the physician is a source of expertise and knowledge. Thus, having more confidence in one's decision may translate into increased confidence in one's ability to collaborate with a healthcare provider (i.e. "I understand my decision and why I am making it, therefore I can discuss it with a healthcare provider."). The findings of the current study are more consistent with those reported in a systematic review of the shared decision-making literature (JosephWilliams et al., 2013), which asserts that the patient's participation in shared decision-making depends not only on the amount of knowledge the patient has regarding the decision, but on the degree of confidence the patient feels in her ability to use that knowledge to make a meaningful contribution to the decision.

When taken altogether to predict total collaborative willingness scores, the five psychological characteristics produced a significant predictive model. This suggests a potential 
mediating or moderating interaction between these variables that allows for them to bolster each other's influence when used collectively to predict collaborative willingness in a medical decision-making context (Field, 2013). Indeed, decision-making is a complex process that may involve the influence of multiple mediating or moderating factors, including, for example, numeracy (Malloy-Weir, Schwartz, Yost, \& McKibbon, 2016), health literacy (Malloy-Weir, Charles, Gafni, \& Entwistle, 2015), and one's personal values (Karel, 2000).

The psychological characteristics were also examined for their ability to predict one's willingness to seek personal involvement in medical decisions, as measured by the Autonomy Preference Index. The Autonomy Preference Index consists of two parts: the six-item general decision-making preference subscale and the decision scenario subscale. Together, these components measure the extent to which the respondent wants the physician to assume complete control over medical decisions. In contrast to the findings when total collaborative willingness scores were predicted, all of the psychological characteristics except intolerance of uncertainty uniquely contributed to the prediction of scores on the decision-making preference subscale. Notably, the direction of the relation between one's decision-making confidence and one's preference for participation in the decision is the opposite of that between confidence and collaborative willingness. Greater decision-making confidence across the three POST decisions was associated with lower scores on the decision-making preference subscale on the Autonomy Preference Index, indicating less preference for making the decision themselves. Conversely, greater confidence was associated with higher total collaborative willingness scores, indicating greater preference for collaboration.

The differences between the prediction of total collaborative willingness scores and Autonomy Preference Index scores may have emerged for a variety of reasons. First, close 
examination of the Autonomy Preference Index decision-making preference subscale reveals that the individual items tend to emphasize the behavior of the respondent's physician, eliciting one's preferences for allowing a physician to have control of a decision pertaining to their own medical condition. Preferences for giving control to the physician with regards to one's health care likely differ from one's willingness to collaborate with the physician when making decisions for someone else. This subtle difference may explain why decision-making confidence did not contribute to higher scores on the Autonomy Preference Index, since the predictor variable of confidence was measured relevant to the decisions that participants made themselves on behalf of another individual across the POST decision tasks. Confidence in one's own decisions may have less relevance with respect to how one considers the decision-making behavior of one's own healthcare provider. Second, participants may have differed with respect to how they considered "collaboration" when responding to the scenarios, which will be further discussed as a limitation of the study. Third, these findings may suggest a fundamental difference, in terms of these psychological characteristics, between one's willingness to collaborate and one's willingness to seek personal involvement in a medical decision-making context.

When scores on the decision scenario subscale of the Autonomy Preference Index were predicted by the five psychological characteristics, the model indicated that all the characteristics contributed significantly to the prediction of the participants' preferences for making the decisions themselves in seven of the nine scenarios. The hypothesis that each of the psychological characteristics would uniquely contribute was not fully supported, as only experiential avoidance uniquely contributed, and only in the first two scenarios that described treatment for the common cold and to routine blood pressure assessments. When examining which items of the Brief Experiential Avoidance Questionnaire were most heavily endorsed, it 
appears that this sample was particularly inclined to avoid "unpleasant memories" and "unpleasant situations" that may provoke a negative emotional experience. Thus, the predictive contribution of experiential avoidance is consistent with current understandings of humans as generally risk-averse (Kahneman \& Tversky, 1984) and, more specifically, with the rationalemotional decision avoidance model proposed by Anderson (2003) that postulates how concern for potential negative emotions affects the degree to which one desires involvement in decisions. In the realm of medical decision-making, interview-based research reveals that patients typically report at least moderate levels of risk aversion that inhibits their ability to make choices about medical care, and that levels of risk aversion can vary by patient race, gender, and education level (Rosen, Tsai, \& Downs, 2003).

In the third decision scenario of the Autonomy Preference Index, which involved hospitalization for a heart condition, consideration of future consequences and confidence were also significant contributors. The predictive contribution of consideration of future consequences may be explained in part by reported relations between this construct and the degree to which individuals talk with their doctor, engage in health behaviors, and gather health information (Joireman, Shaffer, Balliet, \& Strathman, 2012). For example, in an investigation of factors that influence willingness to participate in colorectal cancer screening, Orbell, Perugini, and Rakow (2004) found that those who scored high on a measure of consideration of future consequences were more likely to view participating in the screening, and engaging in subsequent conversations with their healthcare providers, as beneficial. The predictive contribution of confidence is consistent with reported relationships from the shared decision-making literature acknowledging confidence as an important factor in determining whether patients choose to participate in decisions with their physicians. For example, a systematic review conducted by 
Joseph-Williams et al. (2014) investigated patient-reported barriers and facilitators to shared decision-making. Among the variables that were identified across nearly 300 studies, confidence in the value of one's knowledge and personal ability to use that knowledge to contribute to a decision was identified as a significant factor influencing the degree to which patients felt comfortable engaging in shared decision-making.

The differential contribution by the psychological characteristics across the scenarios may be accounted for by differences inherent to the decision scenarios themselves. One possibility would be that the scenarios differ in terms of the immediacy of the risks and potential severity of the consequences associated with each decision. For instance, there is a distinct difference between a situation requiring a decision about the common cold, as in the first Autonomy Preference Index decision scenario in which the risks associated with treatment are relatively minor, and one related to an invasive emergency resuscitative intervention, as in the third decision scenario (CPR).

In their model of decision-making, Sitkin and Weingart (1995) proposed that individuals are more likely to demonstrate risk aversion, by selecting a low-risk decision or one associated with less significant consequences, in situations that carry a greater level of perceived risk. The researchers tested this model by exposing participants to hypothetical situations that required a decision to be made that could potentially influence one's financial and physical well-being. Risk perceptions mediated the effect of any independent situational variables (e.g., the type of problem or the manner in which it was framed) on risky decision-making behavior, such that participants who perceived the decisions as riskier made more risk-averse choices, regardless of the way in which the situations were described (Sitkin \& Weingart, 1995). In the current study, involvement preferences for the third Autonomy Preference Index scenario, which described a 
serious condition involving more intensive treatment and significant long-term consequences relative to the other decision scenarios, were significantly predicted by consideration of future consequences. Given its future orientation, this construct is likely related to how one perceives the potential ramifications of a decision, including the risks and benefits it may carry. Consistent with Sitkin and Weingart's (1995) perspective, individuals who scored higher in consideration of future consequences likely attended to the greater risks and long-term consequences associated with the third Autonomy Preference Index scenario, potentially affecting their involvement preferences.

Another goal of the study was to investigate whether the same five psychological characteristics (intolerance of uncertainty, anxiety, experiential avoidance, consideration of future consequences, and confidence) contributed to the prediction of collaborative willingness for each of the three POST decisions individually. For the regression analysis that addressed this aim, confidence scores pertaining to each specific POST decision were used instead of total confidence scores across all three POST decisions (e.g., for the CPR-related POST decision, only confidence ratings given for the CPR-related decision were included in this model). Each of the three sections of the West Virginia POST, which was modeled in the current study, asks for a different end-of-life treatment preference to be specified: whether to induce CPR or resuscitation if the patient's heart stops, how intensive the "level of care" provided to a patient should be (ranging from "Comfort Measures Only" to "Full Intervention"), and whether to provide artificial fluids or nutrition if the patient becomes unable to eat or drink independently. Similar to the Autonomy Preference Index decision scenarios, each decision differs in terms of the immediacy and significance of the associated risks and potential consequences. For instance, the risks that could result from an emergency rescue intervention like CPR may include cracked ribs, 
brain damage, or a punctured lung. Furthermore, the consequences of not choosing to administer CPR are also immediate and significant (i.e., death), which heightens the stakes associated with this decision.

Interestingly, the model using all five psychological characteristics significantly predicted collaborative willingness only in the POST decision scenario involving CPR. This suggests that collaborative willingness may operate differently across the three POST decisions. Thus, the degree of confidence that an individual has in a decision, the only unique predictor, appears particularly important in determining the extent to which surrogate decision makers seek to collaborate with providers on decisions associated with more immediate and substantial risks, such as a decision involving emergency interventions like CPR.

A potential explanation for this finding may be found in the "social values" theory of self-other decision-making proposed by Stone and Allgaier (2008). These authors found that one's willingness to make risky decisions for another person is influenced by whether risk is considered beneficial in the particular context of the decision. For instance, participants were more likely to make a risky decision for another person in a low-impact relationship situation where risk was considered a less important factor in the decision-making process such that the potential gains appeared to outweigh losses (Stone \& Allgaier, 2008). Collaborating with others, such as the patient's healthcare providers, may help surrogates to inform their risk assessments of patients' situations prior to making a decision. Therefore, surrogates may view collaboration as a more necessary component of the decision-making process in risk-intensive scenarios. Moreover, gaining information through collaboration can reduce the ambiguity surrounding a decisional situation. Ambiguity has been identified as an element that frequently surrounds medical decisions and can prompt unpleasant decisional experiences and increase the likelihood 
of decisional avoidance (Han, Moser, \& Klein, 2007). Although intolerance of uncertainty did not appear as a significant predictor variable in the current study, a more focused examination of ambiguity aversion in surrogate decision-making situations may produce different findings.

The final goal of the study was an exploratory investigation of whether certain demographic variables predicted total collaborative willingness scores across the three POST decision scenarios. The demographic variables of interest included race/ethnicity, age, gender, years of education, and marital status. Only gender was a significant predictor of collaborative willingness scores, with females endorsing greater collaborative willingness than males. This finding is consistent with prior research indicating that women value active approaches to decisions more than men. In an investigation of the degree to which patients preferred involvement in shared decision-making with their physicians, Levinson et al. (2005) found that a greater percentage of women than men preferred active, collaborative decision-making interactions. Similar findings have been reported across the medical decision-making literature, in which women generally seek a more participatory role in managing their health care (Arora \& McHorney, 2000).

\section{Limitations}

Several limitations to the current study should be noted. With respect to generalizability, although recent research promotes the use of Amazon Mechanical Turk as a means of recruiting samples that are more demographically diverse than those recruited through college student or traditional web-based methods (Buhrmester, Kwang, \& Gosling, 2011; Goodman, Cryder, \& Cheema, 2013), certain characteristics of MTurk workers impede the degree to which they can be considered representative of the larger population. For instance, demographic research indicates that MTurk workers are generally more liberal (Shapiro, Chandler, \& Mueller, 2013) 
and less extraverted (Goodman et al., 2013) relative to the general population, both characteristics that could influence how one approaches decisions related to end-of-life or collaboration. However, with the current MTurk sample, the distribution of scores on the predictor and outcome variables did not appear skewed, which ameliorates the concern regarding this limitation.

Another limitation of the current study is the use of the hypothetical surrogate decisionmaking scenarios. Participants may not have responded as they would have in real life when making these medical decisions, since the hypothetical scenarios obviously cannot replicate the exact circumstances surrounding a real medical decision-making situation. Variables such as the degree of familiarity between the surrogate and health-care provider and the elevated anxiety surrounding a real-life decision likely would have produced greater variability in individuals' responses. However, what was lost in generalizability was gained in internal validity. Potential threats to internal validity, such as order effects and selection bias, were minimized through the use of exclusion criteria and a randomized order of measures that included a standardized set of decision scenarios.

Another potential limitation is that participants may have responded as if they were making their own medical decisions, which is a common concern in real-life surrogate decisionmaking situations (Marks \& Arkes, 2008; Vig et al., 2006). While participants were reminded throughout this portion of the survey to consider each decision on behalf of the person who they had nominated, this type of thinking is not intuitive. Despite this concern, the implementation of similar perspective-taking exercises in previous investigations of substituted judgment (Andersson, Holm, Tyran, \& Wengström, 2014; Zikmund-Fisher, Sarr, Fagerlin, \& Ubel, 2006) can bolster one's confidence in the current study's methodology. 
When completing the decision tasks, participants may also have differed in their personal understandings of the concept of collaboration. "Collaboration" was operationally defined in the survey as "the act of working with others to reach a shared decision or goal," but participants may have approached the situation with different goals in mind. As a manipulation check, data was collected regarding participants' intended goals for collaboration through a select-all-thatapply item (See Appendix C). Across the three decision tasks, participants most frequently identified goals for collaboration related to affirming that their decision was appropriate (47.2\% selected this option at least once) and obtaining additional information about the patient's condition (38.0\% selected at least once). However, participants may have considered other goals that were not captured by the data. Furthermore, while using collaboration as a means of deferring personal responsibility for the decision was the least popular choice $(11.2 \%$ selected at least once), social desirability biases may have limited the frequency with which participants self-reported this option, resulting in an underestimate.

Finally, the use of the Autonomy Preference Index may have limited the findings of the current study. As previously discussed, this measure asks respondents to consider the decisionmaking behavior of their own healthcare providers as relevant to their own medical care; thus, the involvement preferences expressed on this measure were provided in relation to one's own medical treatment. This conceptual discrepancy may have accounted for the differences between Autonomy Preference Index involvement preference scores and collaborative willingness ratings on POST hypothetical surrogate decision-making task. Many of the items on the Autonomy Preference Index are also reverse-scored, which is a problematic feature of the measure. 
In general, more research is needed with regards to the main areas addressed by this study: surrogate decision-making and the POST. With more states adopting the use of POST forms (National POLST Paradigm, 2016) and the growing presence of surrogates in medical decision situations (Tejwani et al., 2013), one would hope that more attention will be given to these topics in the future. In particular, findings from the current study point to differences across the three sections of the POST form, which suggests the utility of investigating the elements of each section separately.

With regards to the relation between the POST and the outcome variables of collaborative willingness and desires for personal involvement, future research may investigate if the manner with which the form is introduced to patients or surrogates by healthcare providers influences these behaviors. Surrogates or patients may be more willing to collaborate or assist in making POST decisions with providers who take the time to fully explain and demonstrate their knowledge (Bunn et al., 2018). One could consider whether certain physician characteristics, such as those identified by DiMatteo et al. (1993) and Kaplan et al. (1996), influence surrogates' desires to engage in collaborative decision-making. Qualitative interviews with those who have served as surrogates may confirm the role of these variables or elucidate other variables associated with the decision-making process. The results of this research could inform the training of clinicians that could increase the willingness of surrogates to collaborate.

In addition, further investigation is needed to determine exactly why certain predictor variables, namely intolerance of uncertainty, did not significantly contribute to the two criterion variables, contrary to hypotheses. Mediating or moderating variables that were not accounted for by the current study may be involved, which warrants exploration. Further research with surrogates can also be valuable to elucidate how surrogate decision-making fits into a model of 
decisional behavior, or perhaps necessitates development of a new model that is more specific to surrogate decision-making. Moreover, given the current study's finding that suggests that one's desire for involvement in a medical decision is not necessarily the same as one's willingness to collaborate with a provider on a medical decision, future research may ascertain the nature of the difference between these variables, particularly as they relate to one's overall decision-making confidence.

Practically speaking, health care providers can use findings from studies such as these to better prepare themselves and surrogates for surrogate decision-making encounters. Given the significant role of confidence in predicting engagement in desirable decision-making behaviors like collaboration and active involvement, one may consider ways to improve confidence levels in decision-making situations. The literature provides modest support for the use of decision aids as one method to improve confidence, as one meta-analysis found reports of confidence improvements in roughly half of the included studies that examined the effect of decision aids on confidence levels (Stacey et al., 2017). Providers may consider how to adopt methods to bolster decision-making confidence, such as decision aids, when prompting surrogates to make decisions on behalf of patients. Furthermore, researchers could explore the "framing effect" (Tversky \& Kahneman, 1981; Blumenthal-Barby \& Krieger, 2014) in the context of surrogate decision-making. Physicians could be taught how to present information regarding risks and benefits in such a way as to minimize biased surrogate decision-making (e.g., Almashat, Ayotte, Edelstein, \& Margrett, 2008), an issue that continues to prompt concern among the medical community. 


\section{References}

Adams, J.R., Elwyn, G., Légaré, F., Frosch, D.L. (2012). Communicating with physicians about medical decisions: A reluctance to disagree. Archives of Internal Medicine, 172(15):1184-1186. doi:10.1001/archinternmed.2012.2360

Almashat, S., Ayotte, B., Edelstein, B., \& Margrett, J. (2008). Framing effect debiasing in medical decision making. Patient education and counseling, 71(1), 102-107.

Anderson, C. J. (2003). The psychology of doing nothing: Forms of decision avoidance result from reason and emotion. Psychological Bulletin, 129(1), 139-167. doi:10.1037/00332909.129.1.139

Andersson, O., Holm, H. J., Tyran, J. R., \& Wengström, E. (2014). Deciding for others reduces loss aversion. Management Science, 62(1), 29-36.

Appalachian Legal Services (2000). Health Care Surrogates: What Do I Need to Know? Retrieved April 20 th 2018 . http://www.wvlegalservices.org/surrogat.pdf

Arora, N. K., \& McHorney, C. A. (2000). Patient preferences for medical decision making: who really wants to participate? Medical Care, 38(3), 335-341.

doi:10.1348/014466607X174194

Barry, M. J., \& Edgman-Levitan, S. (2012). Shared decision making - the pinnacle of patientcentered care. New England Journal of Medicine, 366(9), 780-781.

doi:10.1056/nejmp1109283

Bell, L. (2014). Patient-centered care. American Journal of Critical Care, 23(4), 325-325. doi:10.4037/ajcc2014383

Blanchard-Fields, F., Chen, Y., \& Norris, L. (1997). Everyday problem solving across the adult life span: Influence of domain specificity and cognitive appraisal. Psychology and Aging, 12(4), 684. doi:10.1037/0882-7974.12.4.684

Blumenthal-Barby, J. S., \& Krieger, H. (2015). Cognitive biases and heuristics in medical decision making: a critical review using a systematic search strategy. Medical Decision Making, 35(4), 539-557. doi: 10.1177/0272989x14547740

Bryce, C. L., Loewenstein, G., Arnold, R. M., Schooler, J., Wax, R. S., \& Angus, D. C. (2004). Quality of death: Assessing the importance placed on end-of-life treatment in the intensive-care unit. Medical Care, 42(5), 423-431. doi:10.1097/01.mlr.0000124245.62354.57

Buhrmester, M., Kwang, T., \& Gosling, S. D. (2011). Amazon's Mechanical Turk: A new source of inexpensive, yet high-quality, data? Perspectives on psychological science, 6(1), 3-5. doi:10.1037/e527772014-223 
Bunn, F., Goodman, C., Russell, B., Wilson, P., Manthorpe, J., Rait, G., Hodkinson, I., \& Durand, M. A. (2018). Supporting shared decision making for older people with multiple health and social care needs: a realist synthesis. BMC Geriatrics, 18(1), 165. doi: $10.3310 /$ hsdr06280

Carleton, R. N., Mulvogue, M. K., Thibodeau, M. A., McCabe, R. E., Antony, M. M., \& Asmundson, G. J. G. (2012). Increasingly certain about uncertainty: Intolerance of uncertainty across anxiety and depression. Journal of Anxiety Disorders, 26, 468-479. doi:10.1016/j.janxdis.2012.01.011

Carleton, R. N., Norton, M. P. J., \& Asmundson, G. J. (2007). Fearing the unknown: A short version of the Intolerance of Uncertainty Scale. Journal of anxiety disorders, 21(1), 105117. doi:10.1016/j.janxdis.2006.03.014

Chewning, B., Bylund, C. L., Shah, B., Arora, N. K., Gueguen, J. A., \& Makoul, G. (2012). Patient preferences for shared decisions: a systematic review. Patient Education and Counseling, 86(1), 9-18. doi:10.1016/j.pec.2011.02.004

Danis, M., Southerland, L. I., Garrett, J. M., Smith, J. L., Hielema, F., Pickard, C. G., \& Patrick, D. L. (1991). A prospective study of advance directives for life-sustaining care. New England Journal of Medicine, 324(13), 882-888. doi:10.1093/acprof:oso/9780199561636.003.0017

DiMatteo, M. R., Sherbourne, C. D., Hays, R. D., Ordway, L., Kravitz, R. L., McGlynn, E. A., \& Rogers, W. H. (1993). Physicians' characteristics influence patients' adherence to medical treatment: results from the Medical Outcomes Study. Health Psychology, 12(2), 93.

Dugas, M. J., Freeston, M., \& Ladouceur, R. (1997). Intolerance of uncertainty and problem orientation in worry. Cognitive Therapy and Research, 21, 593-606.

Ende, J., Kazis, L., Ash, A., \& Moskowitz, M. A. (1989). Measuring patients' desire for autonomy. Journal of General Internal Medicine, 4(1), 23-30. doi:10.1007/bf02596485

Fagerlin, A., Ditto, P. H., Danks, J. H., \& Houts, R. M. (2001). Projection in surrogate decisions about life-sustaining medical treatments. Health Psychology, 20(3), 166.

doi:10.1037/0278-6133.20.3.166

Field, A. (2013). Discovering statistics using IBM SPSS statistics. Thousand Oaks, CA: Sage.

Freeston, M. H., Rhéaume, J., Letarte, H., Dugas, M. J., \& Ladouceur, R. (1994). Why do people worry?. Personality and Individual Differences, 17(6), 791-802. doi:10.1016/01918869(94)90048-5

Frosch, D. L., \& Kaplan, R. M. (1999). Shared decision making in clinical medicine: past research and future directions. American journal of preventive medicine, 17(4), 285-294. doi:10.1016/s0749-3797(99)00097-5 
Gámez, W., Chmielewski, M., Kotov, R., Ruggero, C., \& Watson, D. (2011). Development of a measure of experiential avoidance: The Multidimensional Experiential Avoidance Questionnaire. Psychological Assessment, 23(3), 692. doi:10.1037/a0023242

Gámez, W., Chmielewski, M., Kotov, R., Ruggero, C., Suzuki, N., \& Watson, D. (2014). The brief experiential avoidance questionnaire: development and initial validation. Psychological assessment, 26(1), 35. doi:10.1037/a0034473

Goodman, J. K., Cryder, C. E., \& Cheema, A. (2013). Data collection in a flat world: The strengths and weaknesses of Mechanical Turk samples. Journal of Behavioral Decision Making, 26(3), 213-224. doi:10.1002/bdm.1753

Gosling, S. D., Vazire, S., Srivastava, S., \& John, O. P. (2004). Should we trust web-based studies? A comparative analysis of six preconceptions about internet questionnaires. American psychologist, 59(2), 93. doi: 10.1037/0003-066x.59.2.93

Greifeneder, R., Bless, H., \& Pham, M. T. (2011). When do people rely on affective and cognitive feelings in judgment? A review. Personality and Social Psychology Review, 15(2), 107-141. doi:10.1177/1088868310367640

Gries, C. J., Curtis, J. R., Wall, R. J., \& Engelberg, R. A. (2008). Family member satisfaction with end-of-life decision making in the ICU. Chest, 133(3), 704-712. doi:10.1378/chest.07-1773

Han, P.K. (2016). The Need for Uncertainty: a case for prognostic silence. Perspectives in Biology and Medicine, 59(4), 567. doi:10.1353/pbm.2016.0049

Han, P. K., Moser, R. P., \& Klein, W. M. (2007). Perceived ambiguity about cancer prevention recommendations: associations with cancer-related perceptions and behaviours in a US population survey. Health Expectations, 10(4), 321-336. doi: 10.1111/j.13697625.2007.00456.x

Han, P. K., Klein, W. M., Lehman, T., Killam, B., Massett, H., \& Freedman, A. N. (2011). Communication of uncertainty regarding individualized cancer risk estimates: Effects and influential factors. An International Journal of the Society for Medical Decision Making, 31(2), 354-366. doi:10.1177/0272989x10371830

Hancock, G. R., Mueller, R. O., \& Stapleton, L. M. (Eds.). (2010). The reviewer's guide to quantitative methods in the social sciences. New York, NY: Routledge.

Hare, J., Pratt, C., \& Nelson, C. (1992). Agreement between patients and their self-selected surrogates on difficult medical decisions. Archives of Internal Medicine, 152(5), 10491054. doi:10.1001/archinte.152.5.1049

Heath, C., \& Gonzalez, R. (1995). Interaction with others increases decision confidence but not decision quality: Evidence against information collection views of interactive decision 
making. Organizational Behavior and Human Decision Processes, 61(3), 305-326. doi:10.1006/obhd.1995.1024

Hickman, S. E., Nelson, C. A., Moss, A. H., Hammes, B. J., Terwilliger, A., Jackson, A., \& Tolle, S. W. (2009). Use of the Physician Orders for Life-Sustaining Treatment (POLST) paradigm program in the hospice setting. Journal of Palliative Medicine, 12(2), 133-141. doi:10.1089/jpm.2008.0196

Howell, J. L., \& Shepperd, J. A. (2016). Establishing an Information Avoidance Scale. Psychological Assessment, 28(12), 1695. doi:10.1037/pas0000315

Informed Medical Decisions Foundation: Tools for Providers. (2012). Retrieved January 29, 2018. Retrieved from https://innovations.ahrq.gov/qualitytools/informed-medicaldecisions-foundation-tools-providers

Jensen, D., Kind, A. J., Morrison, A. S., \& Heimberg, R. G. (2014). Intolerance of uncertainty and immediate decision-making in high-risk situations. Journal of Experimental Psychopathology, 5(2), 178-190. doi:10.5127/jep.035113

Joireman, J., Shaffer, M. J., Balliet, D., \& Strathman, A. (2012). Promotion orientation explains why future-oriented people exercise and eat healthy: Evidence from the two-factor consideration of future consequences-14 scale. Personality and Social Psychology Bulletin, 38(10), 1272-1287. doi:10.1177/0146167212449362

Joseph-Williams, N., Elwyn, G., \& Edwards, A. (2014). Knowledge is not power for patients: a systematic review and thematic synthesis of patient-reported barriers and facilitators to shared decision making. Patient education and counseling, 94(3), 291-309. doi: 10.1016/j.pec.2013.10.031

Kahneman, D. \& Tversky, A. (1984). Choices, values, and frames. American Psychologist, 39(4), 341-50. doi: 10.1037/0003-066x.39.4.341

Kaplan, S. H., Greenfield, S., Gandek, B., Rogers, W. H., \& Ware, J. E. (1996). Characteristics of physicians with participatory decision-making styles. Annals of Internal Medicine, 124(5), 497-504. doi: 10.7326/0003-4819-124-5-199603010-00007

Karel, M. J. (2000). The assessment of values in medical decision making. Journal of Aging Studies, 14(4), 403-422. doi: 10.1016/s0890-4065(00)80005-5

Kelley, K., \& Maxwell, S. E. (2008). Sample size planning with applications to multiple regression: Power and accuracy for omnibus and targeted effects. The SAGE handbook of social research methods, Thousand Oaks, CA: Sage. 
Leahy, R. L., Tirch, D. D., \& Melwani, P. S. (2012). Processes underlying depression: Risk aversion, emotional schemas, and psychological flexibility. International Journal of Cognitive Therapy, 5(4), 362-379. doi:10.1521/ijct.2012.5.4.362

Leo, R. J. (1999). Competency and the capacity to make treatment decisions: a primer for primary care physicians. Primary care companion to the Journal of clinical psychiatry, 1(5), 131. doi:10.4088/pcc.v01n0501

Lerner, J. S., Li, Y., Valdesolo, P., \& Kassam, K. S. (2015). Emotion and decision making. Annual Review of Psychology, 66.

Levinson, W., Kao, A., Kuby, A., \& Thisted, R. A. (2005). Not all patients want to participate in decision making: a national study of public preferences. Journal of general internal medicine, 20(6), 531-535. doi:10.1111/j.1525-1497.2005.04101.x

Limerick, M. H. (2007, March). The process used by surrogate decision makers to withhold and withdraw life-sustaining measures in an intensive care environment. Oncology nursing forum, 34(2). doi:10.1188/07.onf.331-339

Majesko, A., Hong, S. Y., Weissfeld, L., \& White, D. B. (2012). Identifying family members who may struggle in the role of surrogate decision maker. Critical care medicine, 40(8), 2281. doi:10.1097/ccm.0b013e3182533317

Malloy-Weir, L. J., Schwartz, L., Yost, J., \& McKibbon, K. A. (2016). Empirical relationships between numeracy and treatment decision making: A scoping review of the literature. Patient education and counseling, 99(3), 310-325. doi:10.1016/j.pec.2015.10.002

Malloy-Weir, L. J., Charles, C., Gafni, A., \& Entwistle, V. A. (2015). Empirical relationships between health literacy and treatment decision making: a scoping review of the literature. Patient education and counseling, 98(3), 296-309. doi: 10.1016/j.pec.2014.11.004

Maner, J. K., Richey, J. A., Cromer, K., Mallott, M., Lejuez, C. W., Joiner, T. E., \& Schmidt, N. B. (2007). Dispositional anxiety and risk-avoidant decision-making. Personality and Individual Differences, 42(4), 665-675. doi:10.1016/j.paid.2006.08.016

Marks, M. A., \& Arkes, H. R. (2008). Patient and surrogate disagreement in end-of-life decisions: can surrogates accurately predict patients' preferences? Medical Decision Making, 28(4), 524-531. doi: 10.1177/0272989x08315244

McEvoy, P. M., \& Mahoney, A. E. (2012). To be sure, to be sure: Intolerance of uncertainty mediates symptoms of various anxiety disorders and depression. Behavior Therapy, 43(3), 533-545. doi:10.1016/j.beth.2011.02.007 
Miloyan, B., Pachana, N. A., \& Suddendorf, T. (2014). The future is here: A review of foresight systems in anxiety and depression. Cognition \& Emotion, 28(5), 795-810.

doi:10.1080/02699931.2013.863179

Miu, A. C., Heilman, R. M., \& Houser, D. (2008). Anxiety impairs decision-making: psychophysiological evidence from an Iowa Gambling Task. Biological psychology, 77(3), 353-358. doi:10.1016/j.biopsycho.2007.11.010

National Institute on Aging. (2018). Retrieved January 31, 2018, from https://www.nia.nih.gov/

National Institute of Health Care and Excellence (2013). Retrieved August 22, 2018, from https://www.nice.org.uk/guidance/cg174/documents/intravenous-fluid-therapy-niceversion 2.

National POLST Paradigm. (2018). Retrieved January 31, 2018, from http://polst.org/

Orbell, S., Perugini, M., \& Rakow, T. (2004). Individual differences in sensitivity to health communications: consideration of future consequences. Health Psychology, 23(4), 388. doi: $10.1037 / 0278-6133.23 .4 .388$

Patients' Rights Council. (2013). Retrieved January 31, 2018, from http://www.patientsrightscouncil.org/site/advance-directives-definitions/

Pedraza, S. L., Culp, S., Falkenstine, E. C., \& Moss, A. H. (2016). POST forms more than advance directives associated with out-of-hospital death: Insights from a state registry. Journal of Pain and Symptom Management, 51(2), 240-246.

doi:10.1016/j.jpainsymman.2015.10.003

Queen, T. L., Berg, C. A., \& Lowrance, W. (2015). A framework for decision making in couples across adulthood. In T.M. Hess, J. Strough, \& C. Lockenhoff (Eds.) Aging and Decision Making: Empirical and applied perspectives. London, UK: Academic Press. doi:10.1016/b978-0-12-417148-0.00018-2

Robinson, A., \& Thomson, R. (2001). Variability in patient preferences for participating in medical decision making: implication for the use of decision support tools. BMJ Quality \& Safety, 10(1), i34-i38. doi:10.1136/qhc.0100034.

Rosen, A. B., Tsai, J. S., \& Downs, S. M. (2003). Variations in risk attitude across race, gender, and education. Medical Decision Making, 23(6), 511-517. doi:10.1177/0272989X03258431

Schumm, K., Skea, Z., McKee, L., \& N’Dow, J. (2010). 'They're doing surgery on two people': a meta-ethnography of the influences on couples' treatment decision making for prostate cancer. Health Expectations, 13(4), 335-349. doi:10.1111/j.1369-7625.2010.00624.x 
Shalowitz, D. I., Garrett-Mayer, E., \& Wendler, D. (2006). The accuracy of surrogate decision makers: a systematic review. Archives of Internal Medicine, 166(5), 493-497.

doi:10.1001/archinte.166.5.493

Shapiro, D. N., Chandler, J., \& Mueller, P. A. (2013). Using Mechanical Turk to study clinical populations. Clinical Psychological Science, 1(2), 213-220. doi:10.1177/2167702612469015

Silveira, M. J., Kim, S. Y., \& Langa, K. M. (2010). Advance directives and outcomes of surrogate decision making before death. New England Journal of Medicine, 362(13), 1211-1218. doi:10.1056/nejmsa0907901

Silveira, M. J., Wiitala, W., \& Piette, J. (2014). Advance Directive Completion by Elderly Americans: A Decade of Change. Journal of the American Geriatrics Society, 62(4), 706-710. doi:10.1111/jgs.12736

Simon, D., Kriston, L., Loh, A., Spies, C., Scheibler, F., Wills, C., \& Härter, M. (2010). Confirmatory factor analysis and recommendations for improvement of the AutonomyPreference-Index (API). Health Expectations, 13(3), 234-243. doi:10.1111/j.13697625.2009.00584.x

Sitkin, S. B., \& Weingart, L. R. (1995). Determinants of risky decision-making behavior: A test of the mediating role of risk perceptions and propensity. Academy of management Journal, 38(6), 1573-1592. doi: 10.5465/256844

Spatz, E. S., Krumholz, H. M., \& Moulton, B. W. (2016). The new era of informed consent: getting to a reasonable-patient standard through shared decision making. Journal of the American Medical Association, 315(19), 2063-2064. doi:10.1001/jama.2016.3070

Stacey, D., Légaré, F., Lewis, K., Barry, M. J., Bennett, C. L., Eden, K. B., \& Trevena, L. (2017). Decision aids for people facing health treatment or screening decisions. Cochrane database of systematic reviews, (4).

Steenkamp, J. E. M., Hofstede, F., \&Wedel, M. (1999). A cross-national investigation into the individual and national cultural antecedents of consumer innovativeness. Journal of Marketing, 63, 55-69. doi: 10.2307/1251945

Stone, E. R., \& Allgaier, L. (2008). A social values analysis of self-other differences in decision making involving risk. Basic and Applied Social Psychology, 30(2), 114-129. doi:10.1080/01973530802208832

Strathman, A., Gleicher, F. Boninger, D.S., \& Edwards, C.S. (1994). The consideration of future consequences: weighing immediate and distant outcomes of behavior. Journal of Personality and Social Psychology, 66(4), 742. doi:10.1037/0022-3514.66.4.742 
Strough, J., Cheng, S., \& Swenson, L. M. (2002). Preferences for collaborative and individual everyday problem solving in later adulthood. International Journal of Behavioral Development, 26(1), 26-35. doi:10.1080/01650250143000337

Tabachnick, B. G., \& Fidell, L. S. (2001). Multiple regression. Using multivariate statistics, 3, 709-811.

Tejwani, V., Wu, Y., Serrano, S., Segura, L., Bannon, M., \& Qian, Q. (2013). Issues surrounding end-of-life decision-making. Patient preference and adherence, 7, 771.

Torke, A. M., Alexander, G. C., \& Lantos, J. (2008). Substituted judgment: the limitations of autonomy in surrogate decision making. Journal of General Internal Medicine, 23(9), 1514-1517. doi:10.1007/s11606-008-0688-8

Trede, F., \& Higgs, J. (2003). Re-framing the clinician's role in collaborative clinical decision making: re-thinking practice knowledge and the notion of clinician-patient relationships. Learning in Health and Social Care, 2(2), 66-73. doi:10.1046/j.14736861.2003.00040.x

Tversky, A., \& Kahneman, D. (1981). The framing of decisions and the psychology of choice. Science, 211(4481), 453-458. doi: 10.1007/978-1-4613-2391-4_2

United States Census Quick Facts (2017). Retrieved October $4^{\text {th }}, 2018$ from https://www.census.gov/data.html

Vahdat, S., Hamzehgardeshi, L., Hessam, S., \& Hamzehgardeshi, Z. (2014). Patient involvement in health care decision making: a review. Iranian Red Crescent Medical Journal, 16(1). Doi:10.1097/00004010-200701000-00005

Vig, E. K., Taylor, J. S., Starks, H., Hopley, E. K., \& Fryer-Edwards, K. (2006). Beyond Substituted Judgment: How Surrogates Navigate End-of-Life Decision-Making. Journal of the American Geriatrics Society, 54(11), 1688-1693. doi:10.1111/j.15325415.2006.00911.x

Wendler, D., \& Rid, A. (2011). Systematic review: the effect on surrogates of making treatment decisions for others. Annals of Internal Medicine, 154(5), 336-346. doi:10.7326/00034819-154-5-201103010-00008

West Virginia Center for End-of-life Care (2018). Using the POST Form: Guidance for healthcare professionals. Retrieved May $3^{\text {rd }}, 2018$ from http://wvendoflife.org/forpatients/

Wu, G., \& Gonzalez, R. (1999). Nonlinear decision weights in choice under uncertainty. Management science, 45(1), 74-85. doi:10.1287/mnsc.45.1.74 
Zikmund-Fisher, B. J., Sarr, B., Fagerlin, A., \& Ubel, P. A. (2006). A matter of perspective: choosing for others differs from choosing for yourself in making treatment decisions. Journal of General Internal Medicine, 21(6), 618-622. doi: 10.1111/j.15251497.2006.00410.x 
Page intentionally left blank. 
Appendix A

\section{Demographic Questionnaire}

This next section will ask you general question as about yourself and your views.

1. What is your age?

2. To which gender do you most identify? (please choose one)
a. Male
b. Female
c. Transgender male
d. Transgender female
e. Gender variant/Non-conforming
f. Other

3. How many years of education have you completed?

4. What is your marital status? ( please choose one)
a. Single
b. Married/Committed Relationship
c. Separated
d. Divorced
e. Widowed

5. What is your race or ethnic background? (choose all that apply)
a. Caucasian/White
b. African American/Black
c. Asian American
d. Hispanic/Latin American
e. Pacific Islander
f. Native American (American Indian/Alaskan Native)
g. Other

6. Please specify if you selected Other as your answer for question \#5.

7. Have you ever been in a situation in which you were asked by a doctor to make an important medical decision on behalf of another adult (such as your spouse, parent, sibling, adult child, or close friend)? (choose one)
a. Yes
b. No

8. Have you ever participated in making a medical decision for another adult? (choose one)
a. Yes
b. No 
9. How willing would you be to serve in a position where you may be asked by a doctor to make important medical decisions on behalf of another adult (such as your spouse, parent, sibling, adult child, or close friend)? Please use the scale below:

1

(not at all willing)

2

3

(willing)

4

(not willing)

(very willing)

10. To what extent do you think that people typically collaborate with their healthcare providers when making medical decisions?

1

(not at all)
2

(a little)
3

(moderately)
4

(very much so) 
Appendix B

\section{Instructions}

In this activity, you will be asked to make a series of medical decisions as if you have been appointed as a surrogate decision-maker to make medical decisions for a person in your life who is unable to do so.

Take a moment to select an adult from your life who you will consider during the activity (ex: a spouse, parent, sibling, close friend).

When you have your selected person in mind, please answer the following:

The person I am thinking of is my: (choose one) Spouse/Partner

Parent

Sibling

Adult child

Grandparent

Other family member

Close friend

How much do you like this person?

1

(not at all)
2

(a little)
3

(moderately)
4

(very much so)

How much have you talked with this person about end-of-life decisions, including their personal preferences?

1

(not at all)
2

(a little)
3

(moderately)
4

(very much)

Does this person have an advance directive?

$$
\text { Yes } \quad \text { No I don't know }
$$

If you responded "Yes" to the previous question, do you know what their advance directive says (i.e. what preferences the person indicated)?

$$
\text { Yes No }
$$

When reading the following scenarios, imagine the person you selected is the patient and is unable to make his or her own medical decisions due to illness or injury. Imagine that the patient's physicians have informed you that the patient likely has less than a year to live. 
Also imagine that you are serving in a formal surrogate decision-making role where a healthcare provider is asking you to make decisions pertaining to the patient's care. Imagine that the patient's physicians estimate that the patient has less than one year to live.

When making these decisions, select the option that you think the patient would choose if they were able to do so. 


\section{Appendix C}

\section{Part A: CPR}

Decision Prompts (parts A \& C adapted from Hare et al., 1992)

If a patient's heart or breathing stops while in the hospital, an emergency team will be called to try to get the heart and lungs started again. This is called CPR (resuscitation).

Suppose the doctor wants to know whether to try to resuscitate the patient if her/his heart stopped beating. Would you instruct the doctor to attempt CPR?

$$
\text { Yes No }
$$

How confident do you feel in this decision?

1

(not at all confident)
2 (slightly confident)
3

4 (moderately confident) (confident) (very confident)

How confident do you feel that your decision is the decision that the patient would want?

\section{1 2}

(not at all confident) (slightly confident) (moderately confident) (confident) (very confident)

If you were making this decision in real life, how willing would you be to collaborate with the patient's doctors to make the decision? Please consider collaborate as "to work with others to reach a shared decision or goal."

1

(not at all willing)
2

(slightly willing)
3 (moderately willing)
4 (willing) (very willing)

If you would be at least slightly willing to collaborate on this decision, which of the following would be you hope to gain from the collaboration (mark all that apply)?

Additional information pertaining to the patient's condition

Emotional support

Affirmation that my decision is appropriate

Less responsibility for the decision

If you were making this decision in real life, how willing would you be to defer the decision to the patient's doctors (i.e. let the doctors make the decision)?

1

(not at all willing)
2 (slightly willing)
3 (moderately willing)
4 (willing) (very willing) 
If you were making this decision in real life, how willing would you be to take full responsibility for the decision?
1
2
3
4
5
(not at all willing)
(slightly willing)
(moderately willing)
(willing) (very willing)

\section{Part B: Medical Interventions/Levels of Care}

When a patient has a pulse and/or is still breathing, there are different levels of care that can be provided. All levels require that patients be treated with dignity and respect and kept warm, clean, and dry. Comfort Measures allow for the use of medication, wound care and other measures to relieve pain and suffering. No life-sustaining treatment is provided and hospital transfers occur only if comfort needs cannot be met at the current location. Limited Additional Interventions includes the previously described care and allows medical treatment, antibiotics, IV fluids, and cardiac monitoring as indicated. Hospital transfers occur as needed, but the intensive care unit is to be avoided. Intubation and mechanical ventilation is not used. Full Intervention includes the previously described care and allows the use of intubation, mechanical ventilation, advanced airway interventions, and cardioversion. Hospital transfers occur as needed, including to the intensive care unit.

If this were the patient, what level of care would you indicate should be followed? (choose one)

$$
\text { Comfort Measures Limited Additional Interventions Full Interventions }
$$

How confident do you feel in this decision?

$\begin{array}{ccccc}1 & 2 & 3 & 4 & 5 \\ \text { (not at all confident) } & \text { (slightly confident) } & \text { (moderately confident) } & \text { (confident) } & \text { (very confident) }\end{array}$

How confident do you feel that your decision is the decision that the patient would want?

$\begin{array}{lllll}2 & 3 & 4 & 5\end{array}$

(not at all confident) (slightly confident) (moderately confident) (confident) (very confident)

If you were making this decision in real life, how willing would you be to collaborate with the patient's doctors to make the decision? Please consider collaborate as "to work with others to reach a shared decision or goal."

1

(not at all willing)
2

$$
\text { (slightly willing) }
$$

3 (moderately willing)
4 (willing) (very willing) 
If you would be at least slightly willing to collaborate on this decision, which of the following would be you hope to gain from the collaboration (mark all that apply)?

Additional information pertaining to the patient's condition

Emotional support

Affirmation that my decision is appropriate

Less responsibility for the decision

If you were making this decision in real life, how willing would you be to defer the decision to the patient's doctors (i.e. let the doctors make the decision)?

$\begin{array}{ccccc}1 & 2 & 3 & 4 & 5 \\ \text { (not at all willing) } & \text { (slightly willing) } & \text { (moderately willing) } & \text { (willing) } & \text { (very willing) }\end{array}$

If you were making this decision in real life, how willing would you be to take full responsibility for the decision?

$\begin{array}{ccccc}1 & 2 & 3 & 4 & 5 \\ \text { (not at all willing) } & \text { (slightly willing) } & \text { (moderately willing) } & \text { (willing) } & \text { (very willing) }\end{array}$

Part C: Medically administered fluids \& nutrition

A patient who cannot eat can be fed through a nasogastric tube. This tube is placed down the nose and through the esophagus into the stomach. Often the patient has some diarrhea for the first week or two because of the different type of food that is being digested. Other types of artificial feeding methods that can be used are intravenous lines or a tube placed through the belly wall into the stomach.

If the patient were no longer able to eat or drink, would you have the feeding tube placed longterm, for a trial period, or not at all? (choose one)
Long-term
Trial Period
Not at all

Would you have IV fluids administered long-term, for a trial period, or not at all? (choose one)
Long-term
Trial Period
Not at all

How confident do you feel in this decision?

1

2

3

45

(not at all confident) (slightly confident) (moderately confident) (confident) (very confident)

How confident do you feel that your decision is the decision that the patient would want? 
(not at all confident) (slightly confident) (moderately confident) (confident) (very confident)

If you were making this decision in real life, how willing would you be to collaborate with the patient's doctors to make the decision? Please consider collaborate as "to work with others to reach a shared decision or goal."

$\begin{array}{ccccc}1 & 2 & 3 & 4 & 5 \\ \text { (not at all willing) } & \text { (slightly willing) } & \text { (moderately willing) } & \text { (willing) } & \text { (very willing) }\end{array}$

If you would be at least slightly willing to collaborate on this decision, which of the following would be you hope to gain from the collaboration (mark all that apply)?

Additional information pertaining to the patient's condition

Emotional support

Affirmation that my decision is appropriate

Less responsibility for the decision

If you were making this decision in real life, how willing would you be to defer the decision to the patient's doctors (i.e. let the doctors make the decision)?

1

(not at all willing)
2 (slightly willing)
3 (moderately willing)
4 (willing) (very willing)

If you were making this decision in real life, how willing would you be to take full responsibility for the decision?

1 (not at all willing)
2 (slightly willing)
3 (moderately willing)
4 (willing) (very willing) 
Appendix D

Procedure Flow Chart

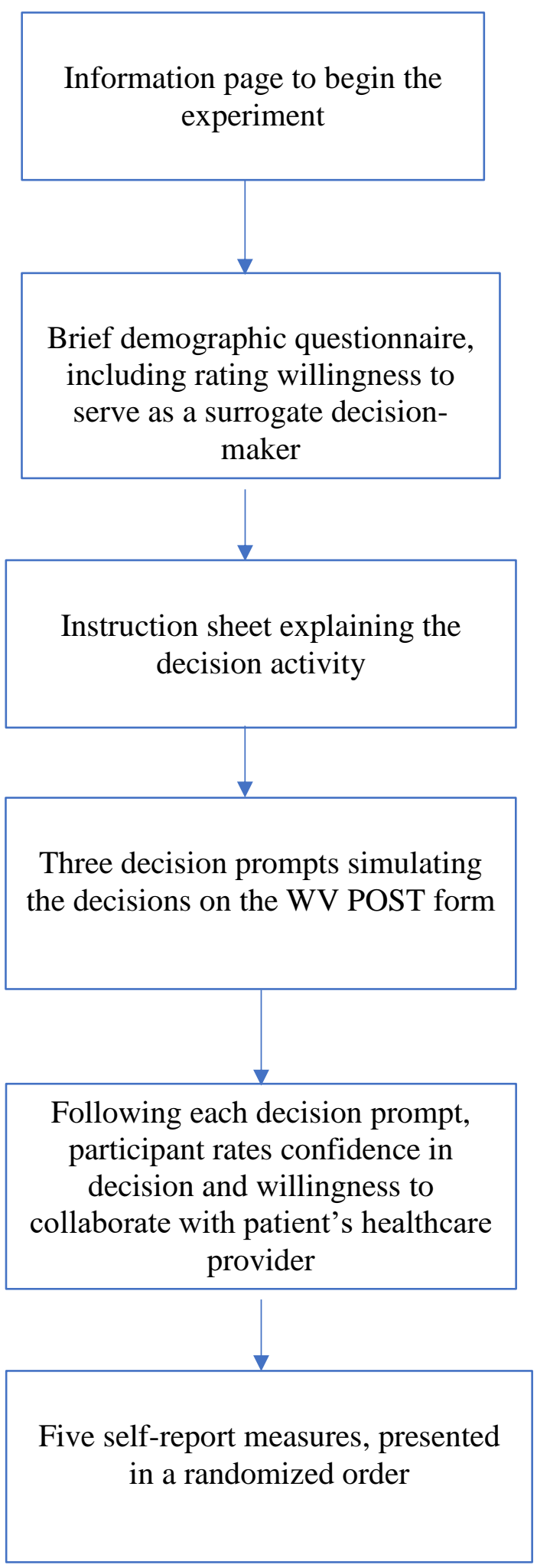


Appendix E

Multiple Regression Analysis Graphic

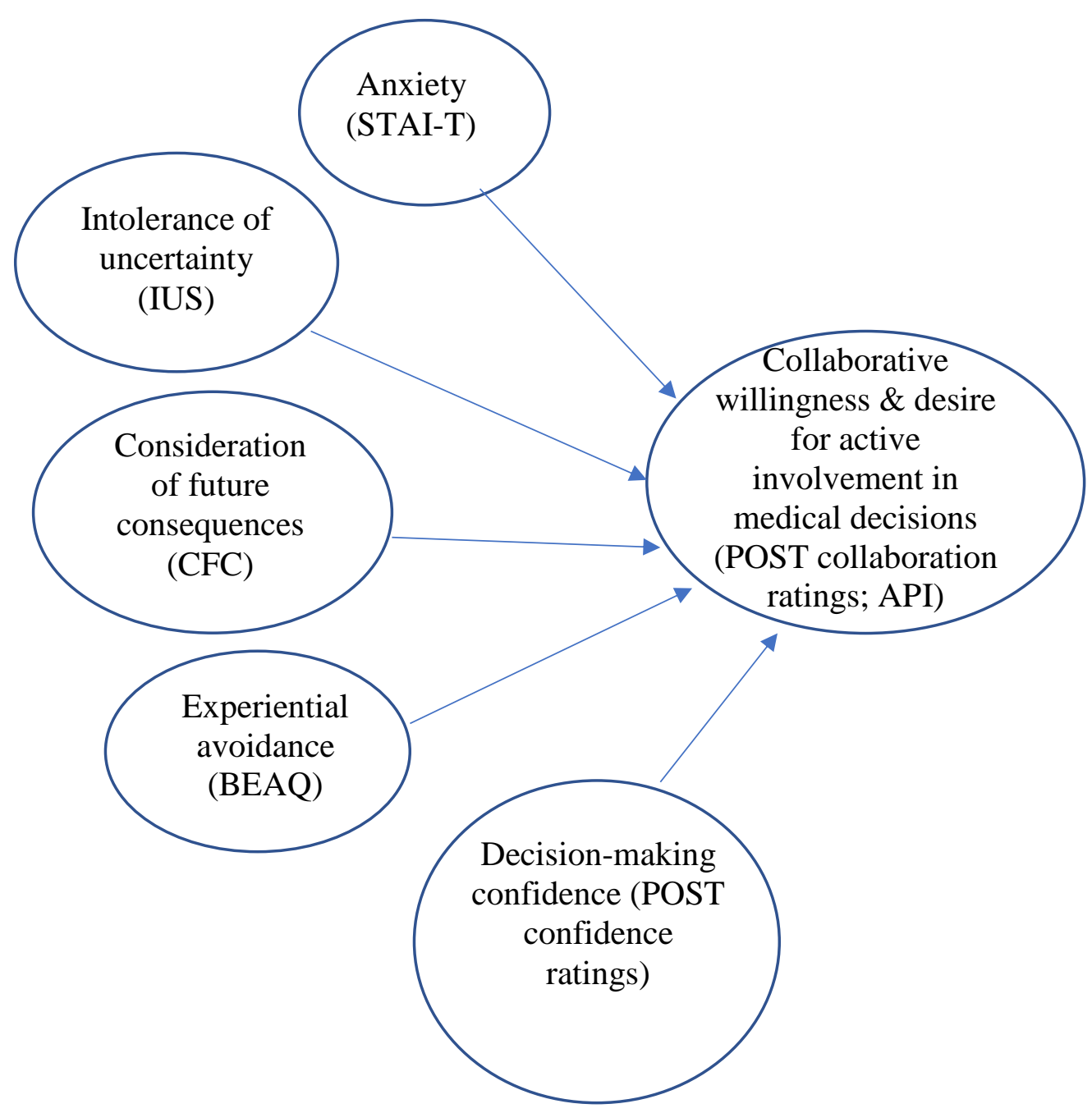


Appendix F

\section{Intolerance of Uncertainty Scale-Short Form (Carleton et al., 2007)}

Please use the scale below to indicate how much each of the following items describes you:

$\begin{array}{lllll}1 & 2 & 3 & 5\end{array}$

(not at all characteristic of me) (entirely characteristic of me)

1. Unforeseen events upset me greatly

2. It frustrates me not having all the information I need.

3. One should always look ahead to avoid surprises.

4. A small, unforeseen event can spoil everything, even with the best planning.

5. I always want to know what the future has in store for me

6. I can't stand being taken by surprise.

7. I should be able to organize everything in advance.

8. Uncertainty keeps me from living a full life.

9. When it's time to act, uncertainty paralyzes me.

10. When I am uncertain, I can't function very well.

11. The smallest doubt can stop me from acting.

12. I must get away from all uncertain situations. 


\section{Appendix $\mathrm{G}$}

\section{Consideration of Future Consequences Scale (Strathman et al., 1994)}

For each of the statements below, please indicate whether or not the statement is characteristic of you. If the statement is extremely uncharacteristic of you (not at all like you) please indicate a "1"; if the statement is extremely characteristic of you (very much like you) please indicate a "5". And, of course, use the numbers in the middle if you fall between the extremes. Please keep the following scale in mind as you rate each of the statements below.

$1=$ extremely uncharacteristic

$2=$ somewhat uncharacteristic

$3=$ uncertain

$4=$ somewhat characteristic

$5=$ extremely characteristic

1. I consider how things might be in the future, and try to influence those things with my day to day behavior.

2. Often I engage in a particular behavior in order to achieve outcomes that may not result for many years.

3. I only act to satisfy immediate concerns, figuring the future will take care of itself.

4. My behavior is only influenced by the immediate (i.e., a matter of days or weeks) outcomes of my actions.

5. My convenience is a big factor in the decisions I make or the actions I take.

6. I am willing to sacrifice my immediate happiness or well-being in order to achieve future outcomes.

7. I think it is important to take warnings about negative outcomes seriously even if the negative outcome will not occur for many years.

8. I think it is more important to perform a behavior with important distant consequences than a behavior with less-important immediate consequences.

9. I generally ignore warnings about possible future problems because I think the problems will be resolved before they reach crisis level.

10. I think that sacrificing now is usually unnecessary since future outcomes can be dealt with at a later time.

11. I only act to satisfy immediate concerns, figuring that I will take care of future problems that may occur at a later date.

12. Since my day to day work has specific outcomes, it is more important to me than behavior that has distant outcomes. 
Appendix H

\section{Brief Experiential Avoidance Questionnaire (Gámez et al., 2013)}

Please use the scale below to indicate how much you agree with each of the following items:

$\begin{array}{cccccc}1 & 2 & 3 & 4 & 5 & 6 \\ \text { (strongly disagree) } & & & & & \text { (strongly agree) }\end{array}$

1. The key to a good life is never feeling any pain.

2. I am quick to leave situations that make me uneasy.

3. When unpleasant memories come to me, I try to put them out of my mind.

4. I feel disconnected from my emotions.

5. I won't do something unless I absolutely have to.

6. Fear or anxiety won't stop me from doing important things.

7. I would give up a lot not to feel bad.

8. I rarely do things that might upset me.

9. It is hard for me to know what I am feeling.

10. I try to put off unpleasant tasks for as long as possible.

11. I go out of my way to avoid uncomfortable situations.

12. One of my big goals is to be free from painful emotions.

13. I work hard to keep out upsetting feelings.

14. If I have any doubts about something, I just won't do it.

15. Pain always leads to suffering. 
Appendix I

Autonomy Preference Index Decision Making Preferences Subscale (Ende et al., 1989)

Please use the scale below to indicate how much you agree with each of the following items:

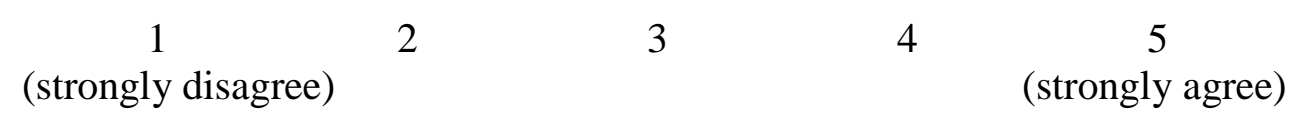

1. The important medical decisions should be made by your doctor, not by you.*

2. You should go along with your doctor's advice even if you disagree with it.*

3. When hospitalized, you should not be making decisions about your own care.

4. You should feel free to make decisions about everyday medical problems.

5. If you were sick, as your illness got worse, you would want your doctor to take greater control.*

6. You should decide how frequently you need a check-up.

Note: *indicates item was reverse scored for current analyses.

\section{Autonomy Preference Index Decision Scenario Subscale (Ende et al., 1989)}

Please use the scale below to indicate how much you agree with each of the following items:

1 = you alone 2 = mostly you 3 = both of you equally 4 = mostly the doctor $5=$ the doctor alone

Cold 1: Suppose you developed a sore throat, stuffy nose, and cough that lasted for three days. You are about to call your doctor on the telephone. Who should decide whether you should be seen by the doctor?

Cold 2: Suppose you developed a sore throat, stuffy nose, and cough that lasted for three days. You are about to call your doctor on the telephone. Who should decide whether a chest X-ray should be taken?

Cold 3: Suppose you developed a sore throat, stuffy nose, and cough that lasted for three days. You are about to call your doctor on the telephone. Who should decide whether you should try taking a cough syrup?

Blood Pressure 1: Suppose you went to your doctor for a routine physical examination and he or she found that everything was all right except that your blood pressure was high (170/100). Who should decide when the next visit to check your blood pressure should be?

Blood Pressure 2: Suppose you went to your doctor for a routine physical examination and he or she found that everything was all right except that your blood pressure was high (170/100). Who should decide whether you should take some time off to relax?

Blood Pressure 3: Suppose you went to your doctor for a routine physical examination and he or she found that everything was all right except that your blood pressure was high (170/100). Who should decide whether you should be treated with medication or diet? 
Heart 1: Suppose you had an attack of severe chest pain that lasted for almost an hour, frightening you enough so that you went to the emergency room. In the ER the doctors discover that you are having a heart attack. Your own doctor is called and you are taken to the intensive care unit. Who should decide how often the nurses should wake you to check your vital signs?

Heart 2: Suppose you had an attack of severe chest pain that lasted for almost an hour, frightening you enough so that you went to the emergency room. In the ER the doctors discover that you are having a heart attack. Your own doctor is called and you are taken to the intensive care unit. Who should decide whether you may have visitors aside from your immediate family?

Heart 3: Suppose you had an attack of severe chest pain that lasted for almost an hour, frightening you enough so that you went to the emergency room. In the ER the doctors discover that you are having a heart attack. Your own doctor is called and you are taken to the intensive care unit. Who should decide whether a cardiologist should be consulted?

Note: All items were reverse-scored for current analyses. 


\section{Table 1}

Demographics

\begin{tabular}{|c|c|c|}
\hline Characteristic & $N$ & $\%$ \\
\hline \multicolumn{3}{|l|}{ Age } \\
\hline $18-33$ years & 32 & $18.6 \%$ \\
\hline $34-49$ years & 39 & $22.7 \%$ \\
\hline $50-64$ years & 58 & $33.1 \%$ \\
\hline 65 years and older & 43 & $25.0 \%$ \\
\hline \multicolumn{3}{|l|}{ Sex } \\
\hline Female & 66 & $38.4 \%$ \\
\hline Male & 106 & $61.6 \%$ \\
\hline \multicolumn{3}{|l|}{ Race/ethnicity } \\
\hline White/Caucasian (not Hispanic) & 108 & $62.8 \%$ \\
\hline Black/African-American & 42 & $24.4 \%$ \\
\hline Asian-American & 7 & $4.1 \%$ \\
\hline Hispanic & 8 & $4.7 \%$ \\
\hline Native American/Pacific Islander & 1 & $.6 \%$ \\
\hline \multicolumn{3}{|l|}{ Marital Status } \\
\hline Single & 42 & $24.4 \%$ \\
\hline Married & 95 & $55.2 \%$ \\
\hline Live-in partner/Committed relationship & 21 & $12.2 \%$ \\
\hline Divorced & 11 & $6.4 \%$ \\
\hline Separated & 1 & $.6 \%$ \\
\hline Widowed & 2 & $1.2 \%$ \\
\hline \multicolumn{3}{|l|}{ Education } \\
\hline $0-12$ years & 31 & $18.0 \%$ \\
\hline $13-18$ years & 122 & $70.9 \%$ \\
\hline 19 years or greater & 19 & $11.0 \%$ \\
\hline
\end{tabular}


Table 2

Predictor and Criterion Variable Descriptive Statistics

\begin{tabular}{|c|c|c|}
\hline Measure & $M$ & $S D$ \\
\hline $\begin{array}{c}\text { Total confidence in POST } \\
\text { decisions }\end{array}$ & 10.78 & 2.60 \\
\hline Intolerance of Uncertainty Scale & 38.18 & 9.86 \\
\hline $\begin{array}{c}\text { Brief Experiential Avoidance } \\
\text { Questionnaire }\end{array}$ & 53.98 & 14.27 \\
\hline $\begin{array}{l}\text { Consideration of Future } \\
\text { Consequences Scale }\end{array}$ & 39.81 & 7.34 \\
\hline $\begin{array}{c}\text { State-Trait Anxiety Inventory- } \\
\text { Trait Subscale }\end{array}$ & 43.56 & 11.72 \\
\hline $\begin{array}{l}\text { Autonomy Preference Index (6- } \\
\text { item decision-making preference } \\
\text { component) }\end{array}$ & 16.58 & 4.36 \\
\hline $\begin{array}{l}\text { Autonomy Preference Index } \\
\text { (decision scenario component) }\end{array}$ & 22.88 & 5.67 \\
\hline $\begin{array}{l}\text { Total collaborative willingness } \\
\text { on POST decisions }\end{array}$ & 10.84 & 2.70 \\
\hline
\end{tabular}




\section{Table 3}

Participant Characteristics as Hypothetical Surrogate Decision makers

Question* $^{*}$

How confident are you that this CPRrelated decision is what the patient would want?

How confident do you feel that this level of care -related decision is what the patient would want?

How confident do you feel that this fluids and nutrition-related decision is what the patient would want?

To what extent have you talked with the patient about end-of-life care?

How much do you like the patient?

How willing would you be to serve in a position where you may be asked by a doctor to make important medical decisions on behalf of another adult?

To what extent do you think that people typically collaborate with their healthcare providers when making medical decisions?
$M$

$S D$

3.95

1.10

3.55

\footnotetext{
*Note: Respondents utilized the same 4-point Likert type scale ranging from " $1=$ not at all" to " $4=$ very much" for these items.
} 
Table 4

Preliminary Correlations among Predictor and Criterion Variables

\begin{tabular}{|c|c|c|c|c|c|c|c|}
\hline & $\begin{array}{c}\text { Collaborative } \\
\text { Willingness } \\
\text { across POST } \\
\text { decisions }\end{array}$ & IUS & BEAQ & $\mathrm{CFC}$ & STAI-T & API & $\begin{array}{c}\text { Confidence } \\
\text { across } \\
\text { POST } \\
\text { decisions }\end{array}$ \\
\hline $\begin{array}{c}\text { Collaborative } \\
\text { Willingness } \\
\text { across POST } \\
\text { decisions }\end{array}$ & & .000 & -.106 & $.248^{* *}$ & $-.173^{*}$ & -.106 & $.351^{* *}$ \\
\hline IUS & .000 & & $.667^{* *}$ & $-.359^{* *}$ & $.589^{* *}$ & -.051 & -.112 \\
\hline BEAQ & -.106 & $.667^{* *}$ & & $-.564^{* *}$ & $.560^{* *}$ & -.005 & $-.254^{* *}$ \\
\hline $\mathrm{CFC}$ & $.248^{* *}$ & $-.359^{* *}$ & $-.564^{* *}$ & & $-.461^{* *}$ & $-.199^{* *}$ & $.332^{* *}$ \\
\hline STAI-T & $-.173^{*}$ & $.589^{* *}$ & $.560^{* *}$ & $-.461^{* *}$ & & -.041 & $-.354^{* *}$ \\
\hline API & -.106 & -.051 & -.005 & $-.199^{* *}$ & -.041 & & $-.297^{* *}$ \\
\hline $\begin{array}{c}\text { Confidence } \\
\text { across POST } \\
\text { decisions }\end{array}$ & $.351^{* *}$ & -.112 & $-.254^{* *}$ & $.332^{* *}$ & $-.354^{* *}$ & $-.297^{* *}$ & \\
\hline
\end{tabular}

Note. ${ }^{* *} p<.01$ (2-tailed)

IUS= Intolerance of Uncertainty Scale. Higher scores indicate greater intolerance of uncertainty $\mathrm{BEAQ}=$ Brief Experiential Avoidance Questionnaire. Higher scores indicate greater experiential avoidance $\mathrm{CFC}=$ Consideration of Future Consequences Scale. Higher scores indicate greater consideration of future consequences

STAI-T=State-Trait Anxiety Inventory-Trait Subscale. Higher scores indicate greater trait-level anxiety API=Autonomy Preference Index decision-making preference and decision scenario subscales. Higher scores indicate greater preferences for personal involvement. 
Table 5

Results of the Multiple Regression Analyses by Autonomy Preference Index Decision Scenario

\begin{tabular}{|c|c|c|c|c|c|c|}
\hline $\begin{array}{l}\text { Decision } \\
\text { Scenario }\end{array}$ & $F$ & $R^{2}$ & Predictor Variable & B & $S E B$ & $\beta$ \\
\hline \multirow[t]{5}{*}{ Cold 1} & \multirow[t]{5}{*}{$14.10^{*}$} & \multirow[t]{5}{*}{.30} & BEAQ* & -.05 & .01 & -.60 \\
\hline & & & Confidence & .02 & .03 & .04 \\
\hline & & & $\mathrm{CFC}$ & .03 & .01 & .16 \\
\hline & & & IUS & .03 & .01 & .22 \\
\hline & & & STAI-T & .01 & .01 & .13 \\
\hline \multirow[t]{5}{*}{ Cold 2} & \multirow[t]{5}{*}{2.01} & \multirow[t]{5}{*}{.06} & BEAQ* & -.02 & .01 & -.23 \\
\hline & & & Confidence & -.03 & .03 & -.08 \\
\hline & & & $\mathrm{CFC}$ & .01 & .01 & .09 \\
\hline & & & IUS & .00 & .01 & .03 \\
\hline & & & STAI-T & .01 & .01 & .06 \\
\hline \multirow[t]{5}{*}{ Cold 3} & \multirow[t]{5}{*}{$12.96^{*}$} & \multirow[t]{5}{*}{.28} & BEAQ* & -.04 & .01 & -.52 \\
\hline & & & Confidence & .02 & .03 & .05 \\
\hline & & & CFC & .00 & .01 & .03 \\
\hline & & & IUS & .02 & .01 & .14 \\
\hline & & & STAI-T & -.01 & .01 & -.11 \\
\hline \multirow{5}{*}{$\begin{array}{c}\text { Blood } \\
\text { Pressure } 1\end{array}$} & \multirow[t]{5}{*}{2.03} & \multirow[t]{5}{*}{.06} & BEAQ* & -.02 & .01 & -.30 \\
\hline & & & Confidence & -.05 & .03 & -.15 \\
\hline & & & $\mathrm{CFC}$ & -.003 & .01 & -.02 \\
\hline & & & IUS & .01 & .01 & .12 \\
\hline & & & STAI-T & -.002 & .01 & -.02 \\
\hline \multirow{5}{*}{$\begin{array}{c}\text { Blood } \\
\text { Pressure } 2\end{array}$} & \multirow[t]{5}{*}{$5.10^{*}$} & \multirow[t]{5}{*}{.13} & BEAQ* & -.03 & .01 & -.36 \\
\hline & & & Confidence & -.06 & .03 & -.14 \\
\hline & & & CFC & .02 & .01 & .11 \\
\hline & & & IUS & .01 & .01 & .06 \\
\hline & & & STAI-T & .00 & .01 & .01 \\
\hline \multirow{5}{*}{$\begin{array}{c}\text { Blood } \\
\text { Pressure } 3\end{array}$} & \multirow[t]{5}{*}{$5.30^{*}$} & \multirow[t]{5}{*}{.14} & BEAQ* & -.02 & .01 & -.31 \\
\hline & & & Confidence & -.11 & .03 & -.28 \\
\hline & & & CFC & -.05 & .01 & -.34 \\
\hline & & & IUS & .01 & .01 & .09 \\
\hline & & & STAI-T & -.02 & .01 & -.18 \\
\hline \multirow[t]{5}{*}{ Heart 1} & \multirow[t]{5}{*}{$8.06^{*}$} & \multirow[t]{5}{*}{.20} & BEAQ & -.004 & .01 & -.05 \\
\hline & & & Confidence* & -.11 & .03 & -.28 \\
\hline & & & $\mathrm{CFC}^{*}$ & -.05 & .01 & -.34 \\
\hline & & & IUS & -.01 & .01 & -.06 \\
\hline & & & STAI-T & -.01 & .01 & -.10 \\
\hline
\end{tabular}


Table 5. Results of the Multiple Regression Analyses by API Decision Scenario

\begin{tabular}{|c|c|c|c|c|c|c|}
\hline $\begin{array}{l}\text { Decision } \\
\text { Scenario }\end{array}$ & $F$ & $R^{2}$ & Predictor Variable & B & $S E \mathrm{~B}$ & $\beta$ \\
\hline \multirow[t]{5}{*}{ Heart 2} & $4.34^{*}$ & .12 & BEAQ* & -.04 & .009 & -.48 \\
\hline & & & Confidence & -.04 & .04 & -.09 \\
\hline & & & $\mathrm{CFC}$ & -.02 & .01 & -.11 \\
\hline & & & IUS & .02 & .01 & .15 \\
\hline & & & STAI-T & .00 & .01 & .01 \\
\hline \multirow[t]{5}{*}{ Heart 3} & $4.61^{*}$ & .12 & BEAQ & -.002 & .01 & -.04 \\
\hline & & & Confidence* & -.11 & .028 & -.31 \\
\hline & & & $\mathrm{CFC}$ & -.02 & .01 & -.16 \\
\hline & & & IUS & -.004 & .01 & -.04 \\
\hline & & & STAI-T & -.008 & .01 & -.11 \\
\hline
\end{tabular}

Note: ${ }^{*}$ Indicates variable uniquely contributed to prediction, $p<.05$

BEAQ: Brief Experiential Avoidance Questionnaire

CFC: Consideration of Future Consequences Scale

IUS: Intolerance of Uncertainty Scale

STAI-T: State-Trait Anxiety Inventory-Trait Subscale 